\title{
1107 穴
}

SoEP papers

on Multidisciplinary Panel Data Research

\section{Industrial Robots, Workers' Safety, and Health}


This series presents research findings based either directly on data from the German SocioEconomic Panel (SOEP) or using SOEP data as part of an internationally comparable data set (e.g. CNEF, ECHP, LIS, LWS, CHER/PACO). SOEP is a truly multidisciplinary household panel study covering a wide range of social and behavioral sciences: economics, sociology, psychology, survey methodology, econometrics and applied statistics, educational science, political science, public health, behavioral genetics, demography, geography, and sport science.

The decision to publish a submission in SOEPpapers is made by a board of editors chosen by the DIW Berlin to represent the wide range of disciplines covered by SOEP. There is no external referee process and papers are either accepted or rejected without revision. Papers appear in this series as works in progress and may also appear elsewhere. They often represent preliminary studies and are circulated to encourage discussion. Citation of such a paper should account for its provisional character. A revised version may be requested from the author directly.

Any opinions expressed in this series are those of the author(s) and not those of DIW Berlin. Research disseminated by DIW Berlin may include views on public policy issues, but the institute itself takes no institutional policy positions.

The SOEPpapers are available at http://www.diw.de/soeppapers

\section{Editors:}

Jan Goebel (Spatial Economics)

Stefan Liebig (Sociology)

David Richter (Psychology)

Carsten Schröder (Public Economics)

Jürgen Schupp (Sociology)

Sabine Zinn (Statistics)

Conchita D'Ambrosio (Public Economics, DIW Research Fellow)

Denis Gerstorf (Psychology, DIW Research Fellow)

Katharina Wrohlich (Gender Economics)

Martin Kroh (Political Science, Survey Methodology)

Jörg-Peter Schräpler (Survey Methodology, DIW Research Fellow)

Thomas Siedler (Empirical Economics, DIW Research Fellow)

C. Katharina Spieß (Education and Family Economics)

Gert G. Wagner (Social Sciences)

ISSN: 1864-6689 (online)

German Socio-Economic Panel (SOEP)

DIW Berlin

Mohrenstrasse 58

10117 Berlin, Germany

Contact: soeppapers@diw.de

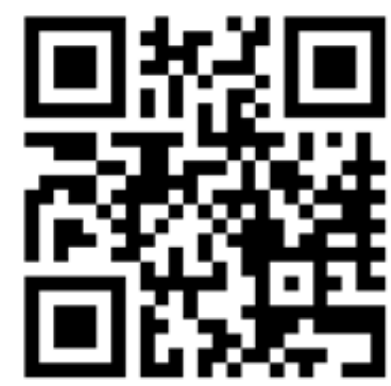




\title{
Industrial Robots, Workers' Safety, and Health*
}

\author{
Rania Gihleb \\ University of Pittsburgh and $\mathrm{IZA}^{\dagger}$ \\ Osea Giuntella \\ University of Pittsburgh and IZA \\ Luca Stella \\ Università Cattolica and IZA ${ }^{\S}$ \\ Tianyi Wang \\ University of Pittsburgh and IZA
}

September 29, 2020

\begin{abstract}
This study explores the relationship between the adoption of industrial robots and workplace injuries using data from the United States (US) and Germany. Our empirical analyses, based on establishment-level data for the US, suggest that a one standard deviation increase in robot exposure reduces work-related injuries by approximately $16 \%$. These results are driven by manufacturing firms $(-28 \%)$, while we detect no impact on sectors that were less exposed to industrial robots. We also show that the US counties that are more exposed to robot penetration experience a significant increase in drug- or alcohol-related deaths and mental health problems, consistent with the extant evidence of negative effects on labor market outcomes in the US. Employing individual longitudinal data from Germany, we exploit within-individual changes in robot exposure and document similar effects on job physical intensity $(-4 \%)$ and disability $(-5 \%)$, but no evidence of significant effects on mental health and work and life satisfaction, consistent with the lack of significant impacts of robot penetration on labor market outcomes in Germany.
\end{abstract}

JEL Codes: I10, J0

Keywords: Robot-Exposure, Work-Related Health Risks

\footnotetext{
*This project has received funding from the European Research Council (ERC) under the European Union's Horizon 2020 research and innovation programme (grant agreement n. 694262), project DisCont - Discontinuities in Household and Family Formation.

†University of Pittsburgh. Email: gihleb@pitt.edu

†University of Pittsburgh. Email: osea.giuntella@pitt.edu.

¿nniversità Cattolica. Email: luca.stella@unicatt.it

ฯUniversity of Pittsburgh. Email: tiw41@pitt.edu
} 


\section{Introduction}

The adoption of industrial robots and artificial intelligence are radically changing the role of workers in the production process, generating lively discussions on their effects on labor markets (Brynjolfsson and McAfee, 2014; Graetz and Michaels, 2018; Acemoglu and Restrepo, 2020; Dauth et al., 2019). However, despite the growing research interest on the effects of robotization, very little is known on how these structural changes to the production process and the allocation of tasks may affect workers' health and workplace safety. The goal of this study is to fill this gap in the extant literature.

The relationship between robots and workers' health and safety is complex. On the one hand, since their introduction, industrial robots have typically been used for physically intensive tasks that are often associated with detrimental effects on health and increased risk of accidents at work. ${ }^{1}$ In this context, automated systems can offer considerable safety benefits to human workers, as robots can help prevent injuries or adverse health effects resulting from working in hazardous conditions. Examples include musculoskeletal disorders due to repetitive or awkward motions (Schneider and Irastorza, 2010), or traumatic injuries (e.g., in poultry processing, where cuts are common). Robots can also prevent multiple hazards in emergency response situations such as chemical spills (Ishida et al., 2006). Besides protecting workers, robots can also minimize risks stemming from human error (Karwowski et al., 1988; Linsenmayer, 1985). If a job is repetitive and monotonous, humans tend to commit a mistake, whereas robots can do these things the same way repeatedly.

On the other hand, robots can pose a variety of hazards to workers (Kirschgens et al., 2018). For example, while industrial robots have been designed to operate at a distance from workers, these machines often lack the sensory capabilities necessary to detect nearby humans. Moreover, the spread of collaborative robots, which are intended to direct interaction and share workspaces with humans, can lead to additional safety risks (Matthias et al., 2011). Qualitative studies raise concerns that the complex relationship between humans and machines may also have detrimental effects on the mental health of the workers (Robelski and Wischniewski, 2018) and might act as an additional stressor at the workplace (Körner et al., 2019; Szalma and Taylor, 2011). Furthermore,

\footnotetext{
${ }^{1}$ See, for instance,

https : //www.designnews . com/automation-motion-control/ robots-keep-workers-dangerous-tasks
} 
the labor market effects of robot adoption and automation may increase stress and anxiety among workers (Venkataramani et al., 2020). Therefore, the direction and the magnitude of the effects of robot adoption on workers' physical and mental health are theoretically ambiguous and represent an open empirical question.

In this study, we investigate this complex relationship using data from the United States (US) and Germany. To examine the impact of robots on work-related injuries in the US, we utilize detailed establishment-level data on work injuries from the Occupational Safety and Health Administration (OSHA) Data Initiative (ODI) covering the 2005 to 2011 period, while information on the distribution of industrial robots across sectors and over time are sourced from the International Federation of Robotics (IFR). We find that a one standard deviation increase in robot exposure reduces work-related injuries by approximately $16 \%$. This result largely reflects a reduction in injuries $(-28 \%)$ at manufacturing firms. Interestingly, we find no significant effects when focusing on the most severe injuries. These results are robust to several sensitivity checks.

We then turn to investigate whether robots have an impact on workers' mental health. Using county-level data on mortality (source: The Centers for Disease Control and Prevention [CDC] Vital Statistics) and survey data on mental health problems (source: Behavioral Risk Factor Surveillance System [BRFSS]), we show that robot penetration leads to sizable increases in drug or alcohol-related deaths and mental health problems. A one standard deviation increase in robot exposure raises deaths due to drug or alcohol abuse by $7 \%$ and the number of days during the previous month when the respondent felt his or her mental health was not good by $17 \%$. However, we find no evidence of significant effects on the suicide rate. We interpret these findings as evidence suggesting that the labor market pressure and fears induced by robot penetration (Acemoglu and Restrepo, 2020) may have detrimental effects on workers' mental health.

Several reasons make Germany an appealing context to explore and complement the analysis conducted using the US establishment and regional data. First, Germany is among the world leaders in robotics (see Figure 1). Second, evidence suggests that the effect of robot penetration on German manufacturing jobs was largely mitigated by the growth of jobs in services, thereby suggesting that the effects on mental health may be different compared to that observed in the US. Third, the availability of longitudinal survey data from the German Socio-Economic Panel 
(SOEP) containing information on occupation, sector, and various health and well-being outcomes allows us to shed further light on the complex effects of robot penetration on workers' safety using individual-level data and exploiting within-individual changes in exposure to robot penetration. Finally, using the SOEP data, we adopt an alternative identification strategy relying on the probability of exposure to robots based on the school track. Thus, we only leverage variation in robot exposure based on the track choice individuals make early in their life. This decision is unlikely to reflect correlates of robots' adoption and labor market outcomes later in life, and therefore, less likely to be endogenous. We find that a one standard deviation increase in robot exposure is associated with a 5\% reduction in the risk of reporting any disability, a $25 \%$ reduction in the risk of accidents at work, and a 4\% reduction in the likelihood of being employed in a highly physically intensive task. We also show no evidence of significant effects of robot exposure on workers' well-being and mental health. Overall, our results for Germany are consistent with those documented by Dauth et al. (2019), who show that robot exposure leads to displacement effects in manufacturing, which is offset by new jobs in services.

Our methodological approach is strictly connected to some recent studies analyzing the impact of robots on labor market conditions, life course choices, and demographic behavior. Recent studies have analyzed the effects of the increase in industrial robot usage on employment and wages across various countries (Acemoglu and Restrepo, 2020; Dauth et al., 2019; Giuntella and Wang, 2019; Graetz and Michaels, 2018). While Acemoglu and Restrepo (2020) and Giuntella and Wang (2019) estimate sizable and negative impacts of the rise in robot exposure on employment and wages across the US commuting zones and China, respectively, Dauth et al. (2019) and Graetz and Michaels (2018) find no significant effects on employment in Germany and for a set of 17 countries, respectively. Recent literature also examines the impact of robotization on family outcomes (Anelli et al., 2019a). In a concurrent study, using data on self-reported health in the US and exposure to robots at the MSA-level, Gunadi and Ryu (2020) find that a 10\% increase in robots per 1,000 workers is associated with approximately a $10 \%$ reduction in the fraction of low-skilled individuals reporting poor health. To the best of our knowledge, this is the only other study analyzing the relationship between robot penetration and physical health. Unlike Gunadi and Ryu (2020), we focus on establishment-level data on work-related injuries and use longitudinal data from Germany on both physical and mental health outcomes of workers. There 
Figure 1: Trends in Robot Adoption in the US, Germany and Europe - 1993-2016

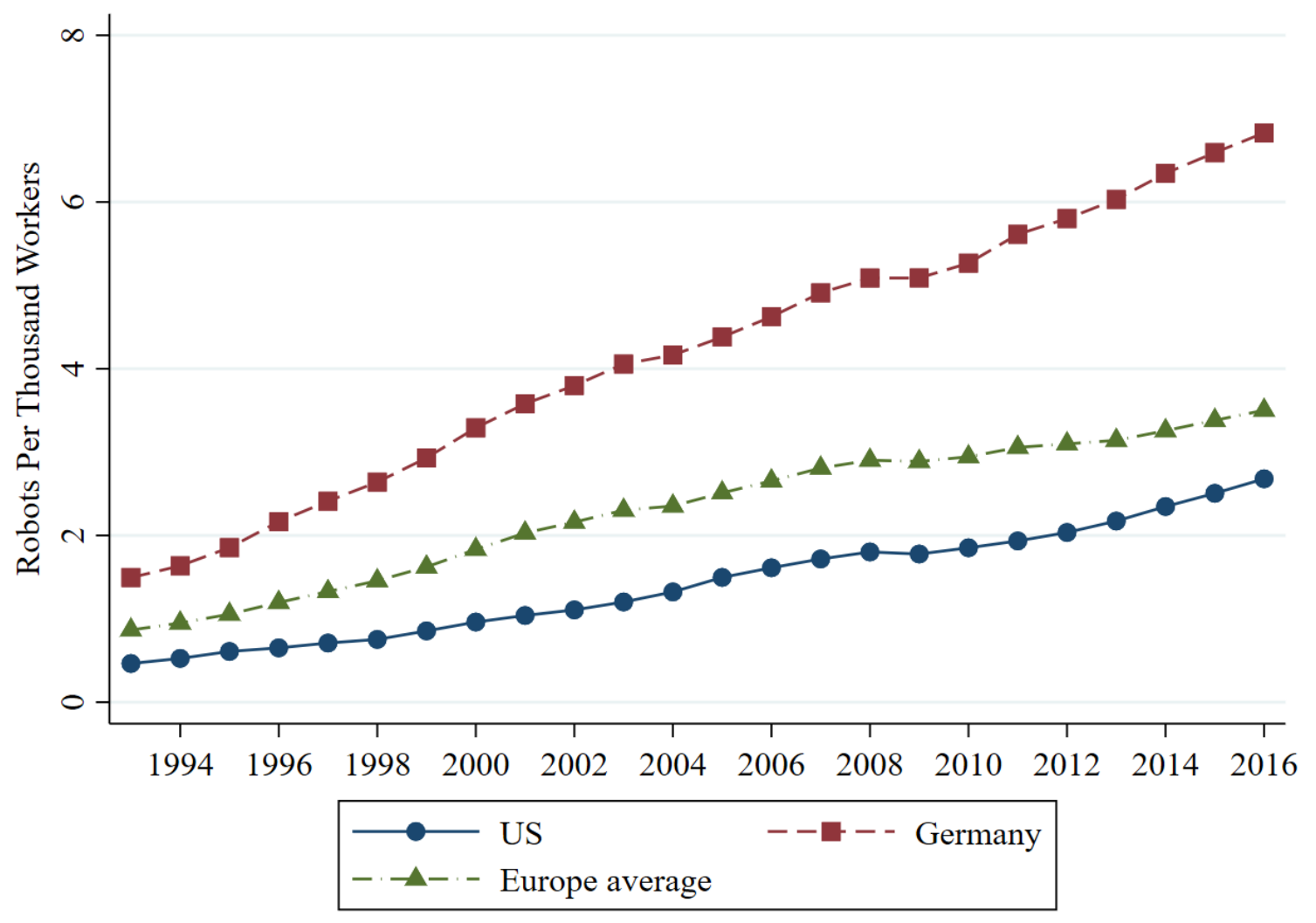

Notes - Data are drawn from the International Federation of Robotics.

are two other recent studies analyzing the relationship between automation and mental health. Venkataramani et al. (2020) find evidence of a strong association between automotive assembly plant closure and opioid overdose mortality between 1999 and 2016. Our evidence on robots exposure is consistent with their findings on automotive plant closures. Using data from Germany, Abeliansky and Beulmann (2019) find evidence of a decline in mental health associated with increased exposure to robots. While the latter study uses similar data for Germany, we adopt a different identification strategy and focus on a broader set of outcomes, and find no evidence of a decline in mental well-being.

By contrast, a growing number of studies investigate the effects of other labor market shocks on injuries and health (Colantone et al., 2019; Hummels et al., 2016; McManus and Schaur, 2016; Giuntella et al., 2019; Giuntella and Mazzonna, 2015). For instance, McManus and Schaur (2016) examine the effect of import competition in the US and find that an increase in import competi- 
tion significantly increases worker injury and illness rates. Further, Hummels et al. (2016) exploit Danish employer-employee data combined with individual health data to demonstrate how rising exports may lead to increases in injuries, severe depression, and hospitalizations because of heart attack and strokes, whereas Colantone et al. (2019) explore the effects of exposure to global trade on mental health.

Our work also appeals to the recent few studies analyzing the effects of immigration on the health of the native population (Giuntella and Mazzonna, 2015; Giuntella et al., 2019). In particular, Giuntella and Mazzonna (2015) find that immigration reduces the likelihood that residents will report negative health outcomes. According to the authors, improvements in natives' average working conditions and workloads help explain the positive effects of immigration on the health of the native population. Similarly, Giuntella et al. (2019) illustrate that immigration significantly reduces natives' physical burden and occupational risk. These studies explore the reallocation of tasks induced by a labor supply shock, that is, the increase in the supply of workers who have less host-specific human capital and may have a comparative advantage in manually intensive tasks (see also Peri and Sparber (2009)). Related to this literature, our study explores the effects of the changes in task allocation induced by robotization, and in particular, its effects on workrelated accidents and mental health. Using Italian administrative data, Leombruni et al. (2013) examine the effects of job displacement on workplace injury risk and earnings. The authors show that displaced workers are exposed to moderate earning losses but experience a substantial increase in workplace injuries. Finally, our study contributes to the literature that investigates the relationship between workers and machines, and their consequences on the health and mental well-being of workers. Robelski and Wischniewski (2018) provide a comprehensive review of the literature on human-machine interaction and physical and mental health, underlining the need for more research on the relationship between health and human-machine interaction.

The remainder of this paper proceeds as follows. Section 2 describes the data. We discuss the empirical strategy in Section 3. The evidence from the establishment and regional data for the US is presented in Section 4. In Section 5, we discuss the data and the empirical strategy, and report the results from the individual-level analysis in Germany. Section 6 concludes. 


\section{Data}

To study the relationship between robotization and workers' health and safety in the US, we employ data from the following sources: ODI, CDC, BRFSS, the American Community Survey (ACS), and IFR.

\subsection{OSHA Data}

Our primary data are drawn from the ODI, which was established by OSHA. A unique feature of the ODI dataset is that it collects data on injuries and illnesses attributable to workrelated activities at the establishment-level. The ODI collects workplace injury and illness data annually from approximately 80,000 private-sector establishments with over 40-60 employees in industries with the highest injury/illness rates in the Bureau of Labor Statistics' Survey of Occupational Injuries and Illnesses, plus all manufacturing industries. The sample excludes industries not regulated by OSHA, such as mining and most government workers. The ODI dataset is an unbalanced panel: different establishments are included every year, with some overlapping across years.

The establishments' data collected by OSHA through ODI present some important limitations. First, for each data collection cycle, OSHA only collects data from $1 \%$ of the total establishments (i.e., approximately 80,000 out of 7.5 million total establishments). Thus, the data are not representative of all businesses. OSHA takes multiple steps to ensure the quality of the data but acknowledges problems and errors may exist for a small percentage of establishments. Finally, not all states participate in the ODI survey. For instance, the data do not contain information for Alaska, Oregon, Puerto Rico, South Carolina, Washington, and Wyoming. Despite these limitations, the ODI dataset represents the only publicly available database including information on national establishment-level occupational injury and illness rates. Furthermore, while the ODI data are more likely to represent high injury and illness rate industries because of the survey exclusion criteria mentioned above, Neff et al. (2008) show that the state-level distributions of its findings do not differ dramatically from those obtained using the Survey of Occupational Injury and Illnesses. Finally, OSHA determines that the database is adequate for longitudinal analysis 
(Neff et al., 2008). ${ }^{2}$

The ODI survey provides data from 1996 to 2011, thereby allowing scholars to study trends and differences in private-sector occupational injury and illness rates. ${ }^{3}$ In addition to including data on the establishment name, address, and industry, the ODI survey provides information on three key safety measurements: the associated total case rate (TCR), the days away, restricted, or transferred (DART) case rate, and the days away from work injury and illness (DAFWII) case rate. We use these safety metrics at the establishment-level as our main outcomes of interest.

In particular, while the TCR reflects the number of work-related injuries per 100 full-time workers during a one-year period, DART includes only those injuries that resulted in days away from work, restricted work activity, or transfers to another job. Formally, DART is calculated using the following formula:

$$
\frac{N}{E H} * 200,000
$$

where $N$ is the number of cases involving days away and/or restricted work activity, and/or job transfers; $E H$ is the total number of hours worked by all employees during the calendar year; and 200,000 is the base number of hours worked for 100 full-time equivalent employees during a one-year period.

DAFWII includes only days away from work per 100 full-time equivalent employees. Thus, it represents the most serious injuries, as cases requiring temporary transfers to another job or restricted work are excluded from this definition. Formally, DAFWII can be written as follows:

$$
\frac{T}{E H} * 200,000
$$

where $T$ is the number of cases involving days away from work; $E H$ and the base number of hours per 100 full-time equivalent employees are defined in the same way as in formula (1).

Summary statistics for the three safety metrics are reported in Panel A of Table A.1 in the Appendix.

\footnotetext{
${ }^{2}$ See also https://clear.dol.gov/study/evaluation-osha\%E2\%80\%99s-impact-workplace-injuries-and-illnessesmanufacturing-using-establishment.

${ }^{3}$ For simplicity, we refer to injuries and illnesses as "injuries."
} 


\subsection{Data on Mortality, Mental Health, and Occupational Burden}

We collect data on the cause of death by county and year from the CDC and the National Center for Health Statistics using the CDC Wonder Online Database. Data are drawn from the detailed mortality file for the years 2005-2011. We restrict attention to deaths associated with drug and alcohol abuse and suicides and compute mortality rates per 100,000 inhabitants.

Information on mentally unhealthy days is drawn from the BRFSS, where individuals are asked to think about their mental health (including stress, depression, and problems with emotions), and report how many days during the last 30 days their mental health was not good. We use county averages for the years 2005-2011.

To measure physical and psychological burden, we employ the ISCO classification from the ACS and the General Index for Job Demands in Occupations constructed by Kroll (2011) and Giuntella et al. (2019), which associates a measure of the physical and psychological burden to each occupation on a 1-10 scale. We then aggregate the data at the commuting zone and year level to obtain the share of workers employed in jobs with a high physical and psychological burden (defined as a score above eight for both physical and psychological burdens). ${ }^{4}$ Panel B of Table A.1 in the Appendix displays summary statistics on mortality, mental health and occupational burden.

\subsection{Robot Data}

Data on the stock of robots by industry, country, and year are drawn from IFR, a professional organization of robot suppliers established in 1987 to promote the robotics industry worldwide. These data are collected through a survey among IFR members, which gathers information on the number of robots that have been sold in a given industry and country. The data cover 70 countries over the period 1993 to 2016, accounting for more than $90 \%$ of the world market for robots. The IFR data report information on the operational stock of "industrial robots," defined as "automatically controlled, reprogrammable, and multipurpose machines" (IFR, 2016). Industrial robots are autonomous machines not operated by humans and can be programmed for several tasks, such as welding, painting, assembling, carrying materials, or packaging. By contrast,

\footnotetext{
${ }^{4}$ Commuting zones can be regarded as local labor market areas.
} 
single-purpose machines, such as coffee machines, elevators, and automated storage systems are not robots based on this definition, because they cannot be programmed to perform other tasks, require a human operator, or both.

The IFR robot data are presently the best available data source on industrial robots. Moreover, this data source has been used by several scholars to analyze the labor market effects of industrial robots (Acemoglu and Restrepo, 2020; Dauth et al., 2019; Giuntella and Wang, 2019; Anelli et al., 2019b; Graetz and Michaels, 2018). Nevertheless, the data do present several limitations. First, we only have information on the number of industrial robots by sectors for a sub-sample of countries for the period 1990-2003. In particular, for the US, the IFR dataset has information on the sectoral distribution of robots only since 2004, although information on the total stock of industrial robots is available since 1993. Second, the industry classifications are coarse with only 13 industrial sectors for manufacturing: food and beverages (1), textiles (2), wood and furniture (3), paper (4), plastic and chemicals (5), glass and ceramics (6), basic metals (7), metal products (8), metal machinery (9), electronics (10), automotive (11), other vehicles (12), and other manufacturing industries (13). For non-manufacturing sectors, data on the operational stock of robots are restricted to six broad categories, namely, agriculture, forestry and fishing, mining, utilities, construction, education, research and development, and other non-manufacturing industries (e.g., services and entertainment). Approximately, a third of the robots are not classified. These unclassified robots were allocated in the same proportion as in the classified data following Acemoglu and Restrepo (2020). An additional limitation of the IFR data is that the geographical information on the distribution of robots is available only at the country level. Nonetheless, we follow previous studies and construct a measure of robot exposure across regions (i.e., commuting zones), which we discuss in detail in the next section.

\section{Empirical Strategy}

To investigate how robot exposure affects workers' health and safety, we estimate the following linear regression model:

$$
Y_{e c t}=\alpha+\beta(\text { Exposure to Robots })_{c t}^{U S}+\tau_{t}+\eta_{c}+\epsilon_{e c t}
$$


where the subscript ect denotes an establishment $e$ located in a commuting zone $c$ in a given year $t$. $Y_{\text {ect }}$ represents one of our workplace safety outcomes of interest, including, for instance, TCR, DART, and DAFWII case rates (detailed in the previous section). Our variable of interest is (Exposure to Robots) ${ }_{c t}^{U S}$, which represents the exposure to robots of a commuting zone $c$ at time $t$. In all our specifications, we standardize our measure of exposure to robots for ease of interpretation.

The model in Equation (3) contains year fixed effects $\left(\tau_{t}\right)$ to account for possible trends in our outcomes. We also include a full set of commuting zone fixed effects $\left(\eta_{c}\right)$ to control for unobservable time-invariant differences across commuting zones that may affect our outcomes of interest. Finally, $\epsilon_{e c t}$ represents an idiosyncratic error term. Throughout the analysis, we cluster standard errors by commuting zone.

We measure robot penetration following Acemoglu and Restrepo (2020) and Anelli et al. (2019b). Therefore, we exploit the pre-existing distribution of employment across commuting zones and industries and multiply it by the national level evolution in the number of robots across industries. As most of the rise in industrial robots in the US occurred after 1990, we choose 1990 as the baseline year. In practice, we compute the ratio of robots to employed workers in industry $s$ at the national level and multiply it by the commuting zone's baseline employment share in sector $s$, and then sum separately for each commuting zone, over all sectors. Formally, our measure of exposure to robots is constructed as follows:

$$
\text { Exposure to } \operatorname{Robots}_{c, t}^{U S}=\sum_{s \in S} l_{c S}^{1990}\left(\frac{R_{s, t}^{U S}}{L_{s, 1990}^{U S}}\right)
$$

where $l_{c s}^{1990}$ denotes the 1990 distribution of employment across industries and commuting zones; $R_{s, t}^{U S}$ identifies the stock of robots in the US across industries in year $t$; and $L_{s, 1990}^{U S}$ represents the total number of individuals (in thousands) employed in sector $s$ in 1990.

Figure 2 documents the geographical variation in the change in robot exposure between 2005 and 2011 across US commuting zones. While the increase in the use of industrial robots was widespread across the US, Figure 2 illustrates the substantial variation in the penetration of robots across commuting zones and over time. Our analysis for the US will thus exploit these 
Figure 2: Industrial Robots across US Counties, $\Delta_{2005-2011}$

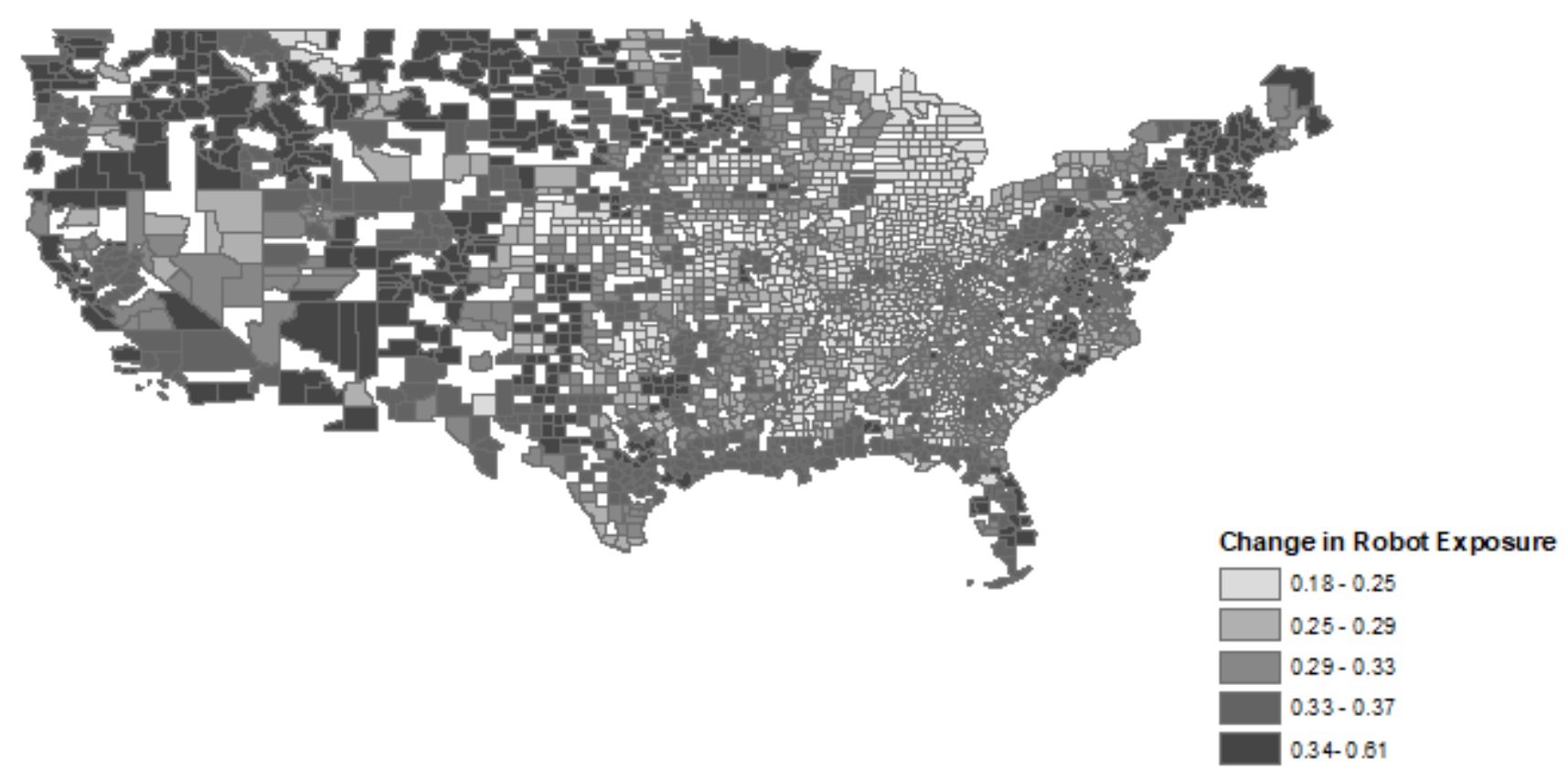

Notes - Data are drawn from the International Federation of Robotics. While we use county-level boundaries, the variation in our measure of robot exposure is at the commuting zone level. 
variations in exposure to robots across commuting zones and over time. Figure 3 illustrates the gradual growth in robot adoptions between 2004 and 2016, comparing manufacturing sectors with all the other industries. Manufacturing (left-axis) has, by far, the highest number of robots per thousand workers (approximately 13 robots per thousand workers in 2016) as opposed to other sectors (approximately 0.2 robots per thousand workers in 2016).

The measure of exposure to robots is based on the initial employment shares in the commuting zone: a Bartik-type instrument. However, to mitigate concerns about the potential correlation of our measure of robot exposure with other factors that may also affect work-related injuries, we follow Acemoglu and Restrepo (2020) and use the industry-level robot installations in other economies, which are meant to proxy improvements in the world technology frontier of robots, as our instrumental variable (IV) for the adoption of robots in the US. In practice, we use the average robot exposure at the industry-level in the nine European countries that are available in the IFR data over the same period. ${ }^{5}$ The underlying idea is to exploit only the variation in the increase in robot adoption across industries of other countries. Formally, we estimate the following equation:

$$
\text { Exposure to Robots }{ }_{c, t}^{I V}=\sum_{s \in S} l_{c s}^{1970}\left(\frac{R_{s, t}^{p 30, E U}}{L_{s, 1990}^{E U}}\right)
$$

where the sum runs over all industries available in the IFR data, $l_{c S}^{1970}$ represents the 1970 share of employment in commuting zone $c$ and industry $s$, as calculated from the 1970 Census, and $\frac{R_{s, t}^{p 30, E U}}{L_{s, 1990}^{E U}}$ denotes the 30th percentile of robot exposure among the above-mentioned European countries in industry $s$ and year $t .^{6}$

Model (3) is estimated using two stage least squares (2SLS), and the first-stage regression is given by:

$$
\sum_{s \in S} l_{c S}^{1990}\left(\frac{R_{s, t}^{U S}}{L_{s, 1990}^{U S}}\right)=\pi_{0}+\pi_{1}\left[\sum_{s \in S} l_{c S}^{1970}\left(\frac{R_{s, t}^{p 30, E U}}{L_{s, 1990}^{E U}}\right)\right]+\delta_{t}+\sigma_{c}+v_{c t}
$$

where $\sum_{s \in S} l_{c S}^{1990}\left(\frac{R_{s, t}^{U S}}{L_{s, 1990}^{U S}}\right)$ is instrumented with $\left[\sum_{s \in S} l_{c S}^{1970}\left(\frac{R_{s, t}^{p 30, E U}}{L_{s, 1990}^{E U}}\right)\right]$, the industry-level robot expo-

\footnotetext{
${ }^{5}$ France, Denmark, Finland, Italy, Germany, Norway, Spain, Sweden, and the United Kingdom.

${ }^{6}$ Following Acemoglu and Restrepo (2020), we used the 30th percentile as the US robot adoption closely follows the 30th percentile of the EU robot adoption distribution.
} 
sure of other countries (i.e., the above-mentioned European countries). $\delta_{t}, \sigma_{c}$, and $v_{c t}$ are defined in the same way as in Model (3).

One may be worried that our measure of robot exposure may be correlated with other economic shocks, particularly to the exposure to import competition from China (Autor and Dorn, 2013). However, Acemoglu and Restrepo (2020) and Anelli et al. (2019a) illustrate that the trade shock is orthogonal to the adoption of robots for both the US and Europe. These studies document how industries that strongly robotized production processes were generally industries that did not offshore production.

Another concern shared with previous studies on this subject (Acemoglu and Restrepo, 2020; Dauth et al., 2019) is that our estimates may largely reflect trends in the automotive industry, which adopted more robots than any other sectors in the period under investigation. This sector may have been subject to specific economic trends, which may confound our relationship of interest, and thus, our reduced form estimates may reflect the effect of a contemporaneous economic shock to that sector (Goldsmith-Pinkham et al., 2020). To partially address this concern, we demonstrate that our measure of robot exposure is not correlated with pre-trends in workrelated injuries. Reassuringly, we also find no evidence of significant effects in sectors that are less exposed to robot penetration (i.e., services). ${ }^{7}$ Furthermore, results are robust to controlling for specific trends across areas with different initial shares of automotive sector employment (see Table A.2 in the Appendix).

We adopt a similar estimation strategy when using individual-level data from Germany. However, as explained in Section 5, in the case of Germany, we use an individual fixed effect strategy, exploiting within-individual variation in exposure to robots over time based on the individual sector as of 1994. Furthermore, we also propose an alternative identification strategy allocating the inflows of robots based on the occupation associated with an individual school track and vocational training, and restrict the sample to individuals who were born before 1980 and thus entered the tracking system in the early '90s.

\footnotetext{
${ }^{7}$ Similarly, we find no significant effects in the finance and public administration sectors. However, given the limited data available from OSHA on these sectors, we excluded them from the analysis (results are available upon request).
} 
Figure 3: Evolution of Industrial Robots in the US, Manufacturing vs. Other Sectors

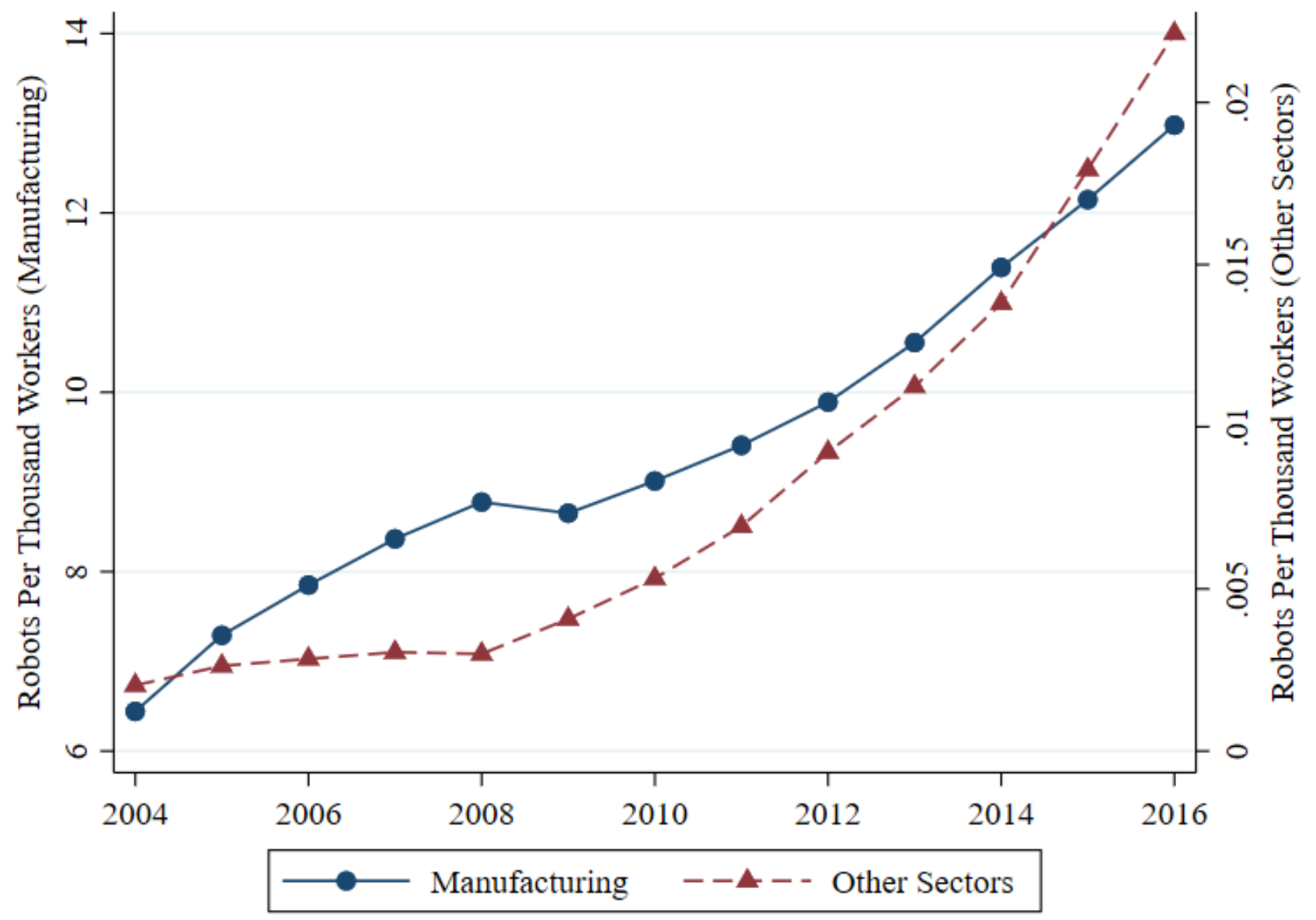

Notes - Data are drawn from the International Federation of Robotics. 


\section{Results}

\subsection{Effects on Work-Related Injuries}

In Table 1, we explore the direct effect of robot exposure on our primary three workplace safety outcomes: TCR, DART, and DAFWII (see Panels A, B, and C, respectively). In these regressions, we use the ODI data and include year and commuting zone fixed effects. Columns 1 and 2 report the ordinary least squares (OLS) and reduced form coefficients, while the 2SLS estimates are presented in column 3. The first-stage F statistic reported at the bottom of each Panel is well above the conventional levels (see also the first stage relationship presented in Table A.3 in the Appendix). The magnitude of 2SLS and OLS estimates is fairly similar. This is not surprising because our measure of robot exposure is already a Bartik-type instrument, which exploits the geographical distribution of sectors in the base-year to allocate robots across US commuting zones.

Overall, Table 1 documents a negative and highly significant impact of robot exposure on TCR. Focusing on the IV estimate in column 3 of Panel A, we find that a one standard deviation increase in our measure of robot exposure decreases the number of workplace injuries by 1.169 per 100 full-time workers during a one-year period, which is equivalent to approximately $16 \%$ of the mean in our sample (7.132 cases per 100 workers). Similarly, as shown in Panel B, establishments based in commuting zones that are more exposed to robot penetration experience a significant reduction in the number of injuries that result in DART. Specifically, a one standard deviation increase in robot exposure decreases the DART rate by $20 \%$ for the mean of the dependent variable (4.187). By contrast, in Panel C, we find no evidence of significant impacts of robot exposure on the most serious injuries, that is, DAFWII.

As a falsification test, when regressing the change in robot exposure between 2005 and 2011 on the change in work-related injuries between 1996 and 2001, we find that the OLS and reduced form coefficients on TCR and DART become much smaller and no longer significant, yielding further support to the causal interpretation of our estimates (see Table 2). ${ }^{8}$

As previously mentioned, we hypothesize that the reduction in injuries may be driven by a

\footnotetext{
${ }^{8}$ ODI data are available since 1996 for TCR and DART. Data on DAFWII for the period 1996-2001 are not available. However, the effects of robot exposure on DAFWII in our baseline estimates were non-significant.
} 
Table 1: Effects of Robot Exposure on Workplace Injuries

\begin{tabular}{|c|c|c|c|}
\hline & $\begin{array}{l}(1) \\
\text { OLS }\end{array}$ & $\begin{array}{c}(2) \\
\text { Reduced form } \\
\end{array}$ & $\begin{array}{c}(3) \\
\text { 2SLS }\end{array}$ \\
\hline \multicolumn{4}{|c|}{ Panel A: Dep. var.: TCR } \\
\hline Robot exposure & $\begin{array}{c}-1.559^{* * *} \\
(0.375)\end{array}$ & & $\begin{array}{c}-1.169^{* * *} \\
(0.321)\end{array}$ \\
\hline Robot exposure - IV & & $\begin{array}{c}-0.495^{* * *} \\
(0.139)\end{array}$ & \\
\hline $\begin{array}{l}\text { Mean of dep. var. } \\
\text { Std. dev. of dep. var. } \\
\text { First stage F statistic }\end{array}$ & $\begin{array}{l}7.132 \\
8.235\end{array}$ & $\begin{array}{l}7.132 \\
8.235\end{array}$ & $\begin{array}{l}7.132 \\
8.235 \\
681.1\end{array}$ \\
\hline \multicolumn{4}{|c|}{ Panel B: Dep. var.: DART } \\
\hline Robot exposure & $\begin{array}{l}-1.010^{* * *} \\
(0.224)\end{array}$ & & $\begin{array}{c}-0.841^{* * *} \\
(0.207)\end{array}$ \\
\hline Robot exposure - IV & & $\begin{array}{c}-0.356^{* * *} \\
(0.088)\end{array}$ & \\
\hline $\begin{array}{l}\text { Mean of dep. var. } \\
\text { Std. dev. of dep. var. } \\
\text { First stage F statistic }\end{array}$ & $\begin{array}{l}4.187 \\
5.429\end{array}$ & $\begin{array}{l}4.187 \\
5.429\end{array}$ & $\begin{array}{l}4.187 \\
5.429 \\
681.1\end{array}$ \\
\hline \multicolumn{4}{|c|}{ Panel C: Dep. var.: DAFWII } \\
\hline Robot exposure & $\begin{array}{l}-0.020 \\
(0.151)\end{array}$ & & $\begin{array}{c}0.132 \\
(0.132)\end{array}$ \\
\hline Robot exposure - IV & & $\begin{array}{c}0.056 \\
(0.057)\end{array}$ & \\
\hline Mean of dep. var. & 2.150 & 2.150 & 2.150 \\
\hline $\begin{array}{l}\text { Std. dev. of dep. var. } \\
\text { First stage F statistic }\end{array}$ & 3.398 & 3.398 & $\begin{array}{l}3.398 \\
681.1\end{array}$ \\
\hline Observations & 445,562 & 445,562 & 445,562 \\
\hline
\end{tabular}

Notes - Data are drawn from the ODI (OSHA) dataset (survey years: 2005-2011). The unit of observation is at the establishment-year level. All models control for commuting zone and year fixed effects. Standard errors are reported in parentheses and are clustered at the commuting zone level.

*Significant at 10 per cent; ${ }^{* *}$ Significant at 5 per cent; ${ }^{* * * S i g n i f i c a n t ~ a t ~} 1$ per cent. 
Table 2: Falsification test: Robot Exposure (2005-2011) and Pre-Trends (1996-2001) in Injuries (Commuting-Zone Level)

\begin{tabular}{|c|c|c|c|c|}
\hline \multirow{4}{*}{ Dep. var.: } & \multirow{2}{*}{\multicolumn{2}{|c|}{$\begin{array}{l}(1) \\
\text { Change in TCR }\end{array}$}} & \multirow{2}{*}{\multicolumn{2}{|c|}{$\begin{array}{l}(3) \\
\text { Change in DART }\end{array}$}} \\
\hline & & & & \\
\hline & \multicolumn{2}{|c|}{$\Delta_{2001-1996}$} & \multicolumn{2}{|c|}{$\Delta_{2001-1996}$} \\
\hline & OLS & Reduced form & OLS & Reduced form \\
\hline Change in robot exposure & 0.003 & & 0.006 & \\
\hline $\begin{array}{l}\text { Change in robot exposure - IV } \\
\left(\Delta_{2011-2005}\right)\end{array}$ & & $\begin{array}{c}0.062 \\
(0.063)\end{array}$ & & $\begin{array}{c}-0.004 \\
(0.030)\end{array}$ \\
\hline Observations & 596 & 596 & 596 & 596 \\
\hline Mean of dep. var. & -0.062 & -0.062 & 0.015 & 0.015 \\
\hline Std. dev. of dep. var. & 1.540 & 1.540 & 0.741 & 0.741 \\
\hline
\end{tabular}

Notes - Data are drawn from the ODI (OSHA) dataset. The unit of observation is at the commuting zone-year level. Standard errors are reported in parentheses and are clustered at the commuting zone level.

*Significant at 10 per cent; ** Significant at 5 per cent; ${ }^{* * * S i g n i f i c a n t ~ a t ~} 1$ per cent.

reallocation of tasks in production, with robot penetration leading workers toward less physically intensive tasks and jobs. In Table 3, we explore the potential mechanism underlying the reduction in occupational injury using ACS data at the commuting zone level over the 2005-2011 period. We find a negative effect on total job burden, measuring both physical and psychological burden. We define high total burden as a dummy variable equal to one if the continuous indicator of total burden is larger than eight (the 75th percentile). However, the coefficient is not precisely estimated. In column 2 , the 2SLS estimate suggests that a one standard deviation increase in robot exposure is associated with a $6.3 \%$ reduction in the likelihood of working in a highly physically intensive occupation (defined as physical burden above 8), whereas we find no evidence of significant effects on the high occupational psychological burden (defined as psychological burden above 8 , see column 3). It is worth noting that this analysis only captures changes across occupations. Previous studies have shown that the reallocation of risk within an occupation title can be significant, and it is likely the case that the adoption of robots induced a reallocation of workers to less physically intensive tasks within a job, and not just a reallocation of workers to different occupational titles (Giuntella and Mazzonna, 2015).

Table 4 reports the 2SLS estimates of the effects or robot exposure on workplace injuries by the industrial sector. Specifically, focusing on TCR as our dependent variable (see Panel 
Table 3: Robot Exposure, Physical and Psychological Burden - 2SLS Estimates

\begin{tabular}{lccc}
\hline \hline & $(1)$ & $(2)$ & $(3)$ \\
Dep. var.: & High total burden & High physical burden & High psychological burden \\
\hline Robot exposure & & & \\
& -0.008 & $-0.015^{* * *}$ & 0.004 \\
& $(0.005)$ & $(0.005)$ & $(0.005)$ \\
& & & \\
Observations & 5,187 & 5,187 & 5,187 \\
Mean of dep. var. & 0.296 & 0.236 & 0.155 \\
Std. dev. of dep. var. & 0.043 & 0.046 & 0.021 \\
First stage F statistic & 577.2 & 577.2 & 577.2 \\
\hline \hline
\end{tabular}

Notes - Data are drawn from the American Community Survey (2005-2011). The unit of observation is at the commuting zone-year level. Standard errors are reported in parentheses and are clustered at the commuting zone level. All models control for commuting zone and year fixed effects.

*Significant at 10 per cent; ${ }^{* *}$ Significant at 5 per cent; ***Significant at 1 per cent.

A), we find that the overall effects are driven by the manufacturing sector (see column 3). A one standard deviation increase in robot exposure reduces the number of workplace injuries in the manufacturing sector by 1.75 per 100 workers, which corresponds to approximately $28 \%$ relative to the mean outcome (6.349). We obtain a similar finding when we consider DART as the dependent variable: the 2SLS estimate reported in column 3 of Panel B suggests that a one standard deviation increase in robot exposure leads to a decrease in DART of about $34 \%$ relative to the average DART. It is reassuring that we find no evidence of significant effects in sectors that are less exposed to the penetration of industrial robots (see column 6). It is worth noting that the health care sector comprises $97 \%$ of the establishments in the service industry surveyed in the ODI dataset.

In what follows, we perform a variety of robustness checks to test how the results change when we modify the sample or use a different specification compared to our benchmark model (see Table 1). First, in Table A.4 in the Appendix, we illustrate that the main results are not affected by the inclusion of state-specific time trends, which are meant to capture unobserved cross-state differences in work-related injuries over time. Second, as individuals may need additional time to adjust their health behavior in response to robot exposure, we re-estimate our baseline specification using a one-year lagged measure of robot exposure as the main explanatory variable (see Table A.5 in the Appendix). Reassuringly, the results substantially confirm the findings presented in our main analysis. Third, in Table A.6 we show that the inclusion of 
Table 4: Effects of Robot Exposure on Workplace Injuries, by Industrial Sector - 2SLS Estimates

\begin{tabular}{|c|c|c|c|c|c|c|}
\hline Sample: & $\begin{array}{c}(1) \\
\text { Agriculture }\end{array}$ & $\begin{array}{c}(2) \\
\text { Construction }\end{array}$ & $\begin{array}{c}\text { (3) } \\
\text { Manufacturing }\end{array}$ & $\begin{array}{c}(4) \\
\text { Transportation }\end{array}$ & $\begin{array}{c}(5) \\
\text { Retail \& Wholesale Trade }\end{array}$ & $\begin{array}{c}\text { (6) } \\
\text { Services }\end{array}$ \\
\hline \multicolumn{7}{|c|}{ Panel A: Dep. var.: TCR } \\
\hline Robot exposure & $\begin{array}{l}-4.822 \\
(3.439)\end{array}$ & $\begin{array}{c}-1.214 \\
(10.303)\end{array}$ & $\begin{array}{l}-1.752^{* * *} \\
(0.372)\end{array}$ & $\begin{array}{c}0.226 \\
(1.173)\end{array}$ & $\begin{array}{c}0.255 \\
(0.533)\end{array}$ & $\begin{array}{l}-0.422 \\
(0.722)\end{array}$ \\
\hline Mean of dep. var. & 7.351 & 6.031 & 6.349 & 7.605 & 7.507 & 10.15 \\
\hline Std. dev. of dep. var. & 8.188 & 7.411 & 7.865 & 7.925 & 6.805 & 10.61 \\
\hline First stage F statistic & 850 & 81.59 & 858.9 & 361.6 & 442.3 & 395.3 \\
\hline \multicolumn{7}{|c|}{ Panel B: Dep. var.: DART } \\
\hline Robot exposure & $\begin{array}{l}-2.611 \\
(2.443)\end{array}$ & $\begin{array}{c}4.848 \\
(5.246)\end{array}$ & $\begin{array}{l}-1.171^{* * *} \\
(0.237)\end{array}$ & $\begin{array}{c}0.057 \\
(0.765)\end{array}$ & $\begin{array}{c}0.324 \\
(0.312)\end{array}$ & $\begin{array}{l}-0.524 \\
(0.607)\end{array}$ \\
\hline Mean of dep. var. & 4.321 & 3.190 & 3.420 & 5.170 & 4.775 & 6.500 \\
\hline Std. dev. of dep. var. & 5.625 & 4.169 & 5.106 & 6.121 & 5.027 & 6.072 \\
\hline First stage F statistic & 850 & 81.59 & 858.9 & 361.6 & 442.3 & 395.3 \\
\hline Observations & 5,373 & 14,819 & 260,306 & 43,755 & 63,100 & 57,951 \\
\hline
\end{tabular}

Notes - Data are drawn from the ODI (OSHA) dataset (2005-2011). The unit of observation is at the establishment-year level. All models control for commuting zone and year fixed effects. Standard errors are reported in parentheses and are clustered at the commuting zone level.

*Significant at 10 per cent; ** Significant at 5 per cent; ${ }^{* * * S i g n i f i c a n t ~ a t ~} 1$ per cent. 
time-varying, commuting-zone level socio-demographic controls, such as the share of women, the average age and the proportion of individuals with a college degree, did not alter the main results. Moreover, while we only have data on the sectoral distribution of robots in the US since 2004, we follow Acemoglu and Restrepo (2020) and use the sectoral distribution of robots in Europe (our IV) to explore the reduced form relationship between robot penetration in Europe and work-related injuries in the US over a longer period (1996-2011). ${ }^{9}$ As displayed in Table A.7, the reduced form point estimates are slightly larger than the ones presented in column 2 of Table 1, suggesting that a one standard deviation in robot exposure reduces TCR by 0.782 cases per 100 workers (equivalent to $7.9 \%$ relative to the mean outcome) and the DART rate by 0.529 cases per 100 workers (equivalent to $9.6 \%$ relative to the mean outcome). Next, we check the sensitivity of the reduced form estimates to the exclusion of the recession period. Overall, the estimates reported in Table A.8 confirm that firms in commuting zones with a higher robot penetration experience decline in work-related injuries.

As a further robustness check, we estimate Model (3) including establishment fixed effects, which allow us to net out the confounding effects of any time-invariant characteristic across establishments. Reassuringly, the 2SLS estimates presented in Panel A of Table A.9 in the Appendix demonstrate that the effects of robot exposure are very similar to the benchmark specification. Finally, we exploit the sectoral information available in the ODI dataset to construct an alternative measure of robot exposure that varies by sector and year. The 2SLS coefficients displayed in Panel B of Table A.9 are overall consistent with those obtained using the geographical measure of robot exposure at the commuting zone level. Specifically, we find that a one standard deviation increase in sectoral robot exposure leads to a 1.649 reduction in the number of injury cases per 100 workers, which is equivalent to a $21.6 \%$ reduction for the mean outcome.

\subsection{Effects on Drug- and Alcohol-Related Deaths and Suicides}

On the one hand, robots may have reduced the risk of injuries and the overall physical intensity of job tasks, while on the other hand, they may have increased job precariousness and workers' uncertainty. Acemoglu and Restrepo (2020) find significant negative effects of robot

\footnotetext{
${ }^{9}$ ODI data are available since 1996 for two of the safety outcomes, namely, TCR and DART.
} 
Table 5: Effects of Robot Exposure on Deaths due to Drug or Alcohol Abuse, Suicide Rate, and Mental Health

\begin{tabular}{|c|c|c|c|}
\hline & $\begin{array}{l}(1) \\
\text { OLS }\end{array}$ & $\begin{array}{c}\text { (2) } \\
\text { Reduced form }\end{array}$ & $\begin{array}{c}(3) \\
2 S L S\end{array}$ \\
\hline \multicolumn{4}{|c|}{ Panel A: Dep. var.: Deaths due to drug or alcohol abuse } \\
\hline Robot exposure & $\begin{array}{c}33.280^{* * *} \\
(7.857)\end{array}$ & & $\begin{array}{l}27.788^{* * *} \\
(8.257)\end{array}$ \\
\hline Robot exposure - IV & & $\begin{array}{c}11.798^{* * *} \\
(3.478)\end{array}$ & \\
\hline $\begin{array}{l}\text { Observations } \\
\text { Mean of dep. var. } \\
\text { Std. dev. of dep. var. } \\
\text { First stage F statistic }\end{array}$ & $\begin{array}{c}18,018 \\
388.6 \\
125\end{array}$ & $\begin{array}{c}18,018 \\
388.6 \\
125\end{array}$ & $\begin{array}{c}18,018 \\
388.6 \\
125 \\
507.6\end{array}$ \\
\hline \multicolumn{4}{|c|}{ Panel B: Dep. var.: Deaths due to suicides } \\
\hline Robot exposure & $\begin{array}{c}0.078 \\
(0.773)\end{array}$ & & $\begin{array}{c}0.250 \\
(0.880)\end{array}$ \\
\hline Robot exposure - IV & & $\begin{array}{c}0.103 \\
(0.367)\end{array}$ & \\
\hline $\begin{array}{l}\text { Observations } \\
\text { Mean of dep. var. } \\
\text { Std. dev. of dep. var. } \\
\text { First stage F statistic }\end{array}$ & $\begin{array}{l}2,819 \\
13.47 \\
5.196\end{array}$ & $\begin{array}{l}2,819 \\
13.47 \\
5.196\end{array}$ & $\begin{array}{l}2,819 \\
13.47 \\
5.196 \\
486.4\end{array}$ \\
\hline
\end{tabular}

Panel C: Dep. var.: Number of mentally unhealthy days

\begin{tabular}{lccc}
\hline Robot exposure & $\begin{array}{c}0.322^{*} \\
(0.195)\end{array}$ & $\begin{array}{c}0.651^{* * *} \\
(0.227)\end{array}$ \\
Robot exposure - IV & & $\begin{array}{c}0.271^{* * *} \\
(0.097)\end{array}$ & \\
& & & \\
Observations & 14,945 & 14,945 & 14,945 \\
Mean of dep. var. & 3.745 & 3.745 & 3.745 \\
Std. dev. of dep. var. & 1.787 & 1.787 & 1.787 \\
First stage F statistic & & & 419.3 \\
\hline \hline
\end{tabular}

Notes - Data on reason of death (Panels A and B) are drawn from Vital Statistics (CDC). Data on the number of mentally unhealthy days are drawn from the BRFSS (Panel C). The unit of observation is at the county-year level. All models control for commuting zone and year fixed effects. Standard errors are reported in parentheses and are clustered at the commuting zone level.

*Significant at 10 per cent; ** Significant at 5 per cent; ***Significant at 1 per cent. 
exposure on income and hours worked, and a positive effect on unemployment. ${ }^{10}$ These results are consistent with the reasoning that at least in the short-run, robots may have increased uncertainty on labor market opportunities, and thus, may have contributed to increased pressure on workers, similar to what is documented when examining the effects of trade and other labor market shocks on workers' mental health (Colantone et al., 2019) and found by Venkataramani et al. (2020) when examining the association between plant closures and opioid overdose mortality.

To analyze the effects of robot exposure on the mental health of workers, we merged the IFR data with county-level data on the reason of death (CDC), and BRFSS data aggregated at the county-level on the number of mentally unhealthy days. We focus on deaths due to drug or alcohol abuse and suicides. The results of this analysis are reported in Table 5.

Panel A of Table 5 documents a positive and significant relationship between the exposure to industrial robots and the rate of deaths due to drug or alcohol abuse. The OLS estimate in column 1 suggests that a one standard deviation increase in robot exposure is associated with an increase of 33.28 cases per 100 workers (equivalent to $8.5 \%$ relative to the mean of the dependent variable). The 2SLS estimate displayed in column 3 is only slightly smaller, suggesting a $7.2 \%$ increase with respect to the mean. In Panel B, we examine the relationship between robot exposure and suicide rates. We find no evidence of significant effects on suicide rate, although the point estimate indicates that areas that are more exposed to robot penetration experience a slight increase in suicide rate $(+1.9 \%) .{ }^{11}$ Similarly, we find a positive but non-significant coefficient when measuring the relationship between robot penetration and psychological burden (see column 3 of Table 3).

Finally, Panel C shows a positive relationship between robot exposure and the number of mentally unhealthy days. The 2SLS estimate in column 3 indicates that a one standard deviation increase in robot exposure leads to a 0.651 increase in the number of days in the past 30 days that individuals reported mental health as not being good, which is equivalent to a $17.4 \%$ increase for the mean outcome.

\footnotetext{
${ }^{10}$ We replicate their analyses on wages and employment and confirm significant negative effects of robot exposure on labor market outcomes. Results are available upon request.

${ }^{11}$ It is worth noting that the sample size reduces substantially, as we only have information on suicides on a restricted sample of counties (542).
} 


\section{Individual-Level Data from Germany}

As mentioned in Section 1, Germany has been a leader in robotics since the early 90s, thereby providing a very interesting context to study the effects of robots on workers' health and safety. Furthermore, the availability of a longitudinal dataset with information on workers' industrial sector, health, and well-being allows us to exploit within-individual variation in the exposure to robots over time and investigate how robots affect workers' health over more than 20 years.

\subsection{Data and Empirical Specification}

\subsubsection{Data}

To analyze the relationship between robot exposure and workers' health and safety in Germany, we employ data from the SOEP, a longitudinal dataset of the German population containing information on a rich set of individual socioeconomic characteristics since $1984 .^{12}$ The SOEP consists of several subsamples and is constructed to ensure it is representative of the entire population of Germany. For a detailed description of the survey, see Wagner et al. (2007) and Goebel et al. (2019). The SOEP provides information on several health metrics (including self-assessed health status, satisfaction with health, and mental and physical health). In this study, we focus on two main health outcomes: a dummy variable equal to one for a doctor-assessed disability, and an indicator variable taking value one if the individual reported a work accident that required treatment by a doctor or at a hospital. While information about disability status is available from 1984 onward, respondents were asked about their accidents at work only during the years between 1987 and 1999. Furthermore, the SOEP data contains information on individual labor market histories and the worker's industrial sector based on the NACE 2-digit classification, which we use to merge with the data on robots from the IFR. To estimate our model, we construct an unbalanced panel of manufacturing and non-manufacturing workers from 1994 through 2016, thereby covering the period for which we have IFR data on the stocks of industrial robots by sector in Germany. ${ }^{13}$

\footnotetext{
${ }^{12}$ The data version used in this paper is SOEP version 35, SOEP, 2020, doi: 10.5684/soep.v35.

${ }^{13}$ While we do have information on robots since 1993, information on disability and work-related injuries is not available in the 1993 SOEP wave.
} 


\subsubsection{Empirical Specification}

To dispel the concern that individual sorting across sectors as a response to robots may invalidate our instrumental strategy, our measure of individual exposure to robot penetration is based on the sector in which workers were employed in $1994 .{ }^{14}$ Thus, our metric of robot penetration in Germany is based on the sector of employment at the baseline. We then follow individuals over time and exploit the within-individual variation over time in robot exposure to identify its effects on the likelihood of reporting any disability, an accident at the workplace, and our measure of occupational physical intensity. We restrict attention to workers aged 18-64 during the years in which outcomes were measured, and exclude self-employed individuals. After these restrictions, we obtain a final longitudinal sample containing 64,358 person-year observations resulting from 6,228 individuals. Table A.10 in the Appendix reports descriptive statistics on the main variables used in the analysis. Figure 4 illustrates the trends in robot adoption in Germany, comparing manufacturing industries vs. all the other sectors. As is evident from the figure, there is a marked difference in the levels of robot penetration between manufacturing and the other sectors, while the growth rate is relative similar.

We estimate the following linear regression model:

$$
Y_{i j r t}=\alpha+\beta(\text { Exposure to Robots })_{j t}^{G E}+\lambda X_{i t}+\gamma_{i}+\tau_{t}+\eta_{r}+\epsilon_{i j r t}
$$

where the index ijrt denotes an individual $i$, working in IFR sector $j$ in federal state $r$ at the year of interview $t$. The outcome variable $Y_{i j r t}$ represents an indicator variable for an individual who reported either a disability or an accident at the workplace, high physical burden (defined as a dummy variable if the physical burden is above 8), high psychological burden (defined as a dummy taking the value one if the psychological burden is above 8), work satisfaction, and life satisfaction. Our variable of interest is (Exposure to Robots) $j_{t}$, which represents the robot adoption in industry $j$ and year $t$. In the vector $X_{i r t}$, we include worker-level covariates, such as a full set of age dummies, gender, and indicators for education and marital status. We account for the longitudinal nature of the SOEP data by including worker fixed effects $\left(\gamma_{i}\right)$, and

\footnotetext{
${ }^{14}$ Individuals who were unemployed in 1994 were assigned their first available industrial sector. Results are substantially identical if we restrict the sample to individuals employed in 1994 and assign robot exposure based on their occupation in 1994 (available upon request).
} 
Figure 4: Evolution of Industrial Robots in Germany, Manufacturing vs. Other Sectors (19942016)

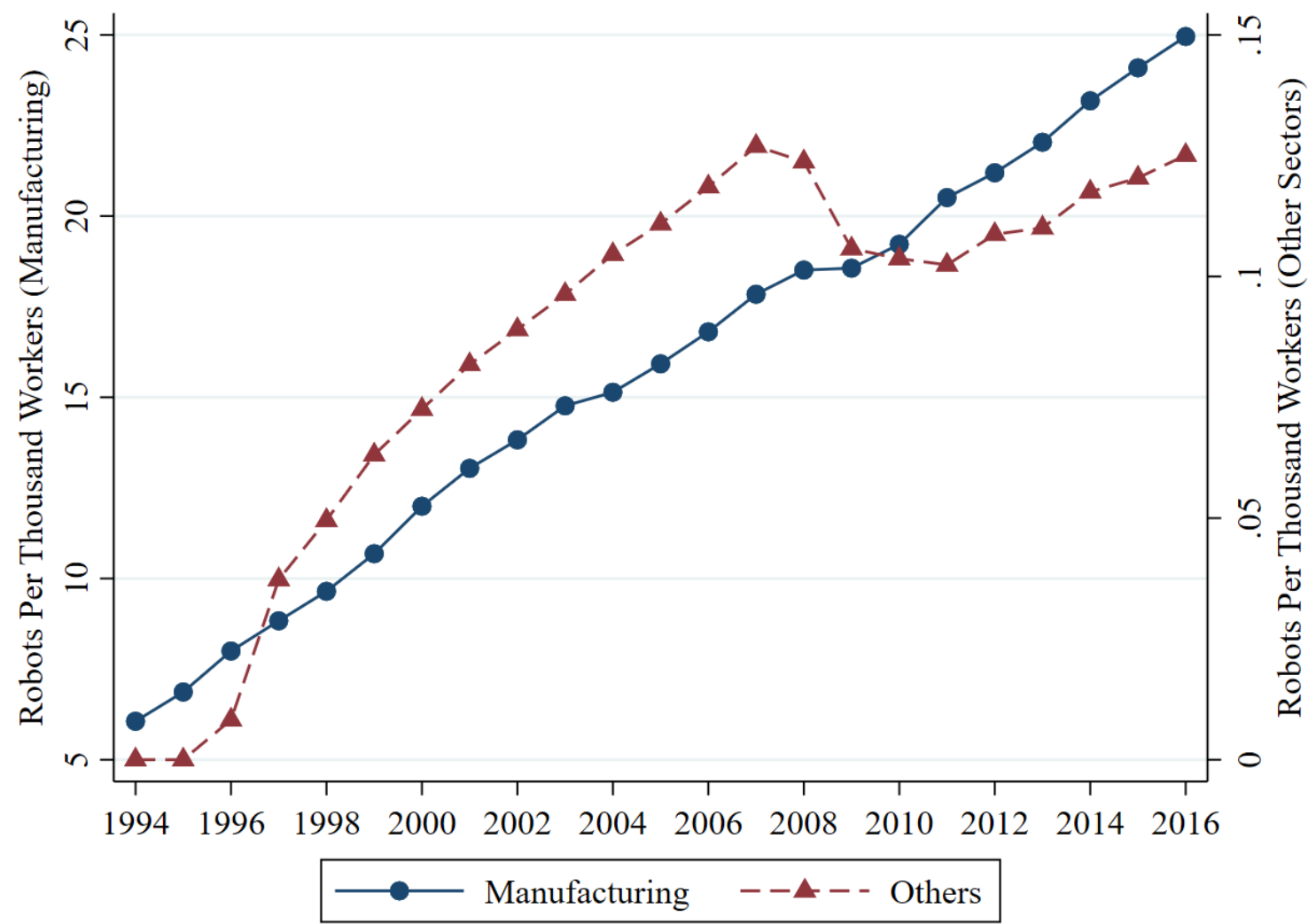


thus, control for unobservable, time-constant differences among workers. We then instrument our measure of robot exposure in Germany using the average robot adoptions across industries in other high-income countries as an instrument. In particular following Dauth et al. (2019), we use data from Spain, Finland, France, Norway, Sweden, and the United Kingdom, and employ the mean sectoral exposure in these countries to construct our instrument. ${ }^{15}$ Additionally, we control for survey year fixed effects $\left(\tau_{t}\right)$ to account for possible trends in our outcomes as well as a set of federal state dummies $\left(\eta_{r}\right)$, which are meant to capture unobservable, timeinvariant differences across states that may influence individuals' health outcomes. Finally, $\epsilon_{i j s t}$ represents a disturbance term. In all our specifications, we use the available sampling weights, and standardize our measure of exposure to robots for ease of interpretation.

\subsection{Exploiting German Tracking System}

Tracking decision in Germany occurs at the transition from primary and secondary schooling (Krause and Schüller, 2014; Zimmermann et al., 2013). Primary schools cover four grades and pupils are aged ten years when they are tracked into three different school paths: a) lower secondary school (Hauptschule), preparing students for manual and blue-collar professions; b) intermediate secondary school (Realschule), preparing students for administrative and lower white-collar jobs; and c) upper secondary school (Gymnasium), lasting three years longer and preparing students for higher education, allowing for direct access to universities. This decision is made jointly by parents and teachers, with teachers recommending a secondary school track to parents. This recommendation is however not binding in most states, and students are allowed to move between school tracks at any grade, although only a very small percentage (less than 2\%) do so (Dustmann et al., 2017).

This institutional feature of the German school system allows us to propose an alternative empirical strategy based on the tracking system. We exploit the school track choice to construct a probabilistic measure of robot exposure, which is a weighted average of the sectoral robot exposure, where the weight is given by the relative probability of working in a given sector conditional on a school track. Furthermore, we restrict the sample to individuals born before 1980 to focus on those who entered a track in the early 1990s, further mitigating the concern

\footnotetext{
${ }^{15}$ Using the median we obtain similar results.
} 
of endogeneity concerning future robot inflows by sector. ${ }^{16}$ In this respect, the SOEP includes a set of variables designed to provide information on the occupation associated with vocational training. Since 1985, respondents are asked if they have left education since the beginning of the year before the survey and which degrees they have obtained. This information is used for the generation of the variable on the occupation associated with vocational training. Similarly, since 2001 this information is collected among respondents filling the biography questionnaire The SOEP data combines these two types of information. Restricting the sample to individuals reporting information on their school track, we construct a probabilistic measure of exposure to robots based on their school path. Our measure of exposure to robots is then calculated as follows:

$$
\text { Exposure to } \operatorname{Robots}_{o, t}^{G E}=\sum_{j \in j} \lambda_{o j}\left(\frac{R_{j, t}^{G E}}{L_{j, 1990}^{G E}}\right)
$$

where $R_{j, t}^{G E}$ represents the stock of robots in Germany across industries in year $t$; and $L_{j, 1990}^{G E}$ is the total number of individuals (in thousands) employed in sector $j$ in 1990. $\lambda_{o j}$ denotes the probability that an individual works in sector $j$ given his/her initial occupation associated with vocational training. In practice, we collect information from all individuals in the SOEP with non-missing information on the occupation associated with vocational training.

This allows us to only exploit variation in robot exposure based on the track choice individuals made in school, which is unlikely to be correlated with future trends in robot adoption over time, and thus, could alleviate the concerns of selection and omitted variable bias. To conduct this approach, we include all workers reporting information on their school track and do not restrict the sample to those employed in 1994 to maximize the sample size, as information on school track is only available for a sub-sample of respondents. Notice that information on the occupation associated with vocational training is asked to a very limited sample of individuals before 2001, since the retrospective information was not collected before 2001 (SOEP, 2019). This prevents us from using work-related injuries as an alternative outcome, as this variable is available only until 1999.

\footnotetext{
${ }^{16}$ We obtain similar results restricting the sample to individuals born before 1975 , although the sample size shrinks substantially. While the effect on disability remains unchanged, the point estimate on physical burden is similar but less precisely estimated.
} 


\subsection{Results}

Table 6 reports the OLS (see Panel A) and 2SLS estimates (see Panel B) of the effects of robot exposure on several outcomes measuring workers' health and safety: disability, risk of accidents at work, high physical burden, high psychological burden, work satisfaction, and life satisfaction. As described in the previous section, we include individual-level covariates, individual fixed effects, as well as state and year dummies in each regression. Focusing on the OLS results, we find that a one standard deviation increase in robot exposure is associated with a $5 \%$ reduction in the risk of reporting any disability (see column 1), a 32\% reduction in the risk of work accidents (see column 2), and a $4 \%$ reduction in the likelihood of being employed in a highly physically intensive task (see column 4). ${ }^{17}$ By contrast, we find no evidence of significant effects of robot exposure on high total burden (see column 3) and mental health (see columns 5-7). The 2SLS coefficients in Panel B are overall very similar to the corresponding OLS estimates. Reassuringly, in Table 7 we find no evidence of significant effects when examining the impact of robot exposure between 1994 and 2000 on lagged values of disability, work accidents, and physical burden covering the 1984-1990 period, thereby providing further support to a causal interpretation of our findings.

Using the measure of exposure based on the school track and vocational training and restricting the sample to individuals born before 1980 (see Table 8), qualitatively we largely confirm the findings presented in Table 6. Point estimates are larger, suggesting that an increase in one standard deviation exposure to robots reduces the likelihood of reporting any disability by 1.4 percentage points (see column 1), equivalent to a $26 \%$ reduction. Similarly, the likelihood of working in a highly physically demanding job declines by 3.1 percentage points (see column 2 ), equivalent to a $18 \%$ reduction. These larger estimates are not particularly surprising as by exploiting vocational training we focus on a sample of workers who were more likely to be exposed to robot penetration. Thus, the coefficients capture a local average treatment effect on this particular population. At the same time, we confirm the lack of negative effects on mental health (see columns 3-5), and if anything, we find evidence of a 5\% increase in work satisfaction. We obtain similar results when including any individual with information on the occupation associ-

\footnotetext{
${ }^{17}$ These effects are similar for men and women and larger among medium and high-skilled workers. Results are available upon request.
} 


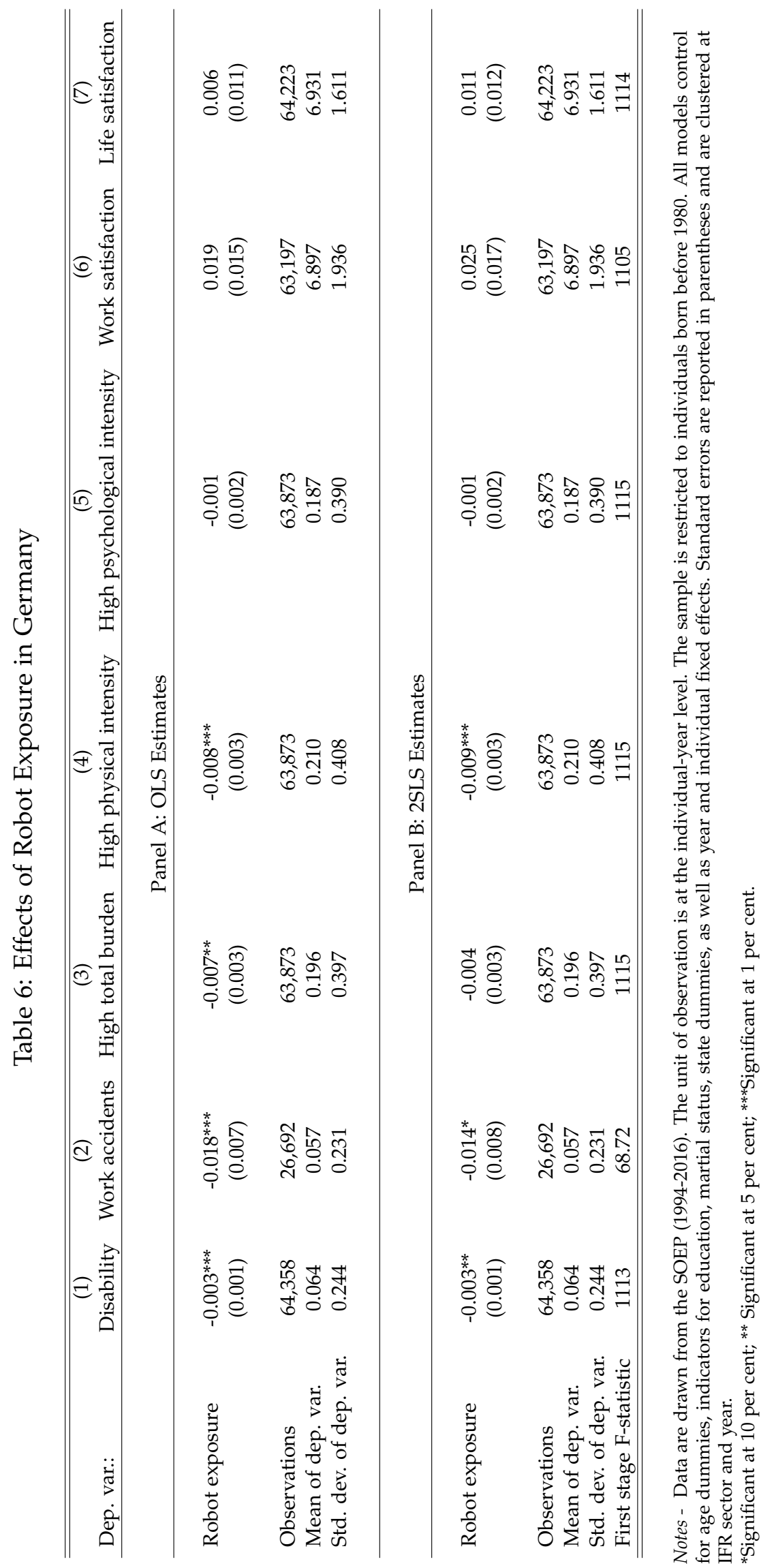


Table 7: Falsification Test: Robot Exposure (1994-2000) and Pre-Trends (1984-1990) in Health, Work Accidents, and Physical Burden

\begin{tabular}{lccc}
\hline \hline Dep. var.: & $\begin{array}{c}(1) \\
\text { Disability } \\
1984-1990\end{array}$ & $\begin{array}{c}(2) \\
\text { Work accidents } \\
1984-1990\end{array}$ & $\begin{array}{c}(3) \\
\text { High physical burden } \\
1984-1990\end{array}$ \\
\hline & \multicolumn{3}{c}{ Panel A: OLS Estimates } \\
\hline Robot exposure & 0.001 & -0.004 & 0.002 \\
(1994-2000) & $(0.003)$ & $(0.016)$ & $(0.008)$ \\
& & & \\
Observations & 18,625 & 8,643 & 18,057 \\
Mean of dep. var. & 0.057 & 0.066 & 0.288 \\
Std. dev. of dep. var. & 0.231 & 0.249 & 0.453 \\
& & & \\
& & & \\
& Panel B: 2SLS Estimates & \\
& & & \\
Robot exposure & 0.004 & -0.032 & -0.009 \\
(1994-2000) & $(0.003)$ & $(0.025)$ & $(0.012)$ \\
& & & \\
Observations & 18,625 & 8,643 & 0.288 \\
Mean of dep. var. & 0.057 & 0.066 & 0.453 \\
Std. dev. of dep. var. & 0.231 & 0.249 & 83.92 \\
First stage F-statistic & 82.63 & 30.74 & \\
\hline \hline
\end{tabular}

Notes - Data are drawn from the SOEP (1984-2016). The unit of observation is at the individual-year level. All models control for age dummies, indicators for education, martial status, state dummies, as well as year and individual fixed effects. Information on disability is available for the years 1984-1989, while information on work accidents is available for the years 1987-1989. Standard errors are reported in parentheses and are clustered at IFR sector and year.

*Significant at 10 per cent; ** Significant at 5 per cent; ***Significant at 1 per cent. 
ated with vocational training and do not restrict the sample to individuals born before 1980 (see Table A.11 in the Appendix).

Table 8: Effects of Robot Exposure in Germany - Exposure based on Vocational Training

\begin{tabular}{|c|c|c|c|c|c|c|}
\hline Dep. var.: & $\begin{array}{c}(1) \\
\text { Disability }\end{array}$ & $\begin{array}{c}(2) \\
\text { High total burden }\end{array}$ & $\begin{array}{c}\text { (3) } \\
\text { High physical burden }\end{array}$ & $\begin{array}{c}\text { (4) } \\
\text { High psychological burden }\end{array}$ & $\begin{array}{c}(5) \\
\text { Work satisfaction }\end{array}$ & $\begin{array}{c}(6) \\
\text { Life satisfaction }\end{array}$ \\
\hline Robot exposure & $\begin{array}{c}-0.014^{* *} \\
(0.007)\end{array}$ & $\begin{array}{l}-0.001 \\
(0.011)\end{array}$ & $\begin{array}{c}-0.031^{* *} \\
(0.013)\end{array}$ & $\begin{array}{l}-0.010 \\
(0.012)\end{array}$ & $\begin{array}{c}0.392^{* * *} \\
(0.127)\end{array}$ & $\begin{array}{c}0.008 \\
(0.081)\end{array}$ \\
\hline Observations & 27,411 & 27,233 & 27,233 & 27,233 & 26,171 & 26,640 \\
\hline Mean of dep. var. & 0.054 & 0.203 & 0.172 & 0.201 & 7.175 & 7.400 \\
\hline Std. dev. of dep. var. & 0.225 & 0.402 & 0.378 & 0.400 & 2.038 & 1.622 \\
\hline
\end{tabular}

Notes - Data are drawn from the SOEP. Individual-level specification over the period 1994-2016. Standard errors are reported in parentheses and are clustered at IFR sector and year. All models control for age dummies, indicators for education, martial status, state dummies, as well as year and individual fixed effects.

*Significant at 10 per cent; ${ }^{* *}$ Significant at 5 per cent; ${ }^{* * * S i g n i f i c a n t ~ a t ~} 1$ per cent.

We view our results as being consistent with those documented by Dauth et al. (2019), who show that robot adoption leads to displacement effects in manufacturing, which is offset by new jobs in services. It is worth noting that while we focus on drug and alcohol use related deaths in the US, here, we focus on job psychological burden and self-reported metrics of mental health. We do not have information on causes of death, and unfortunately, the small sample size of our panel would not allow us to conduct this analysis using our longitudinal data.

\section{Conclusion}

In this study, we explore the relationship between the penetration of industrial robots and work-related injuries using data from the US and Germany. Using the US establishment-level data from OSHA, we find that a one standard deviation increase in robot exposure reduces workrelated injuries by $16 \%$. These results are driven by manufacturing firms $(-28 \%)$, while we find no significant effects for sectors that do not adopt industrial robots (i.e., services). In contrast, we find no evidence of a significant reduction when focusing on the most severe injuries. At the same time, areas that are more exposed to robot penetration experience higher rates of drug- or alcoholrelated deaths $(-7.2 \%)$ and mentally unhealthy days $(-17.4 \%)$. Overall, these results are consistent with reduced job physical intensity $(-6.3 \%)$ and increased economic uncertainty (Acemoglu and Restrepo, 2020). Employing individual-level data from Germany, we exploit within-individual 
variation in the exposure to robots over time and propose an alternative identification strategy exploiting information on school tracking and vocational training. We find similar results on job physical intensity and health but no evidence of significant effects on mental health, which appears consistent with the findings of Dauth et al. (2019), who document how the rise of new jobs in services offset the displacement effects in the manufacturing sector in Germany.

Overall, our results highlight the complex relationship between the adoption of these new technologies and the physical and mental health of workers in the sectors that are most exposed to robot adoption. Previous studies have often emphasized the negative effects robots may have on labor market outcomes. Our findings suggest that we should pay attention to the significant mental health consequences of these labor market shocks. Yet, we should not discount the potential beneficial effects of robots on workplace safety.

Future research could shed further light on how the adoption of robots affect the reallocation of tasks within firms and occupations. Understanding the complex interaction between workers and robots in the workplace goes beyond the scope of this study. The relationship between robot exposure and workers' mental health calls for a more in-depth study exploiting granular data and rich information on firms' practices and employees' well-being. 


\section{References}

Abeliansky, Ana and Matthias Beulmann, "Are they coming for us? Industrial robots and the mental health of workers," Industrial Robots and the Mental Health of Workers (August 16, 2019), 2019.

Acemoglu, Daron and Pascual Restrepo, "Robots and jobs: Evidence from US labor markets," Journal of Political Economy, 2020, 128 (6), 2188-2244.

Anelli, Massimo, Italo Colantone, and Piero Stanig, "We were the robots: Automation and voting behavior in western europe," BAFFI CAREFIN Centre Research Paper, 2019, (2019-115).

_ , Osea Giuntella, and Luca Stella, "Robots, Labor Markets, and Family Behavior," IZA Discussion Paper, 2019.

Autor, David and David Dorn, "The growth of low-skill service jobs and the polarization of the US labor market," American Economic Review, 2013, 103 (5), 1553-97.

Brynjolfsson, Erik and Andrew McAfee, The second machine age: Work, progress, and prosperity in a time of brilliant technologies, WW Norton \& Company, 2014.

Colantone, Italo, Rosario Crino, and Laura Ogliari, "Globalization and mental distress," Journal of International Economics, 2019, 119, 181-207.

Dauth, Wolfgang, Sebastian Findeisen, Jens Suedekum, and Nicole Woessner, "The Adjustment of Labor Markets to Robots," University of Würzburg, 2019.

Dustmann, Christian, Patrick A Puhani, and Uta Schönberg, "The long-term effects of early track choice," The Economic Journal, 2017, 127 (603), 1348-1380.

Giuntella, Osea and Fabrizio Mazzonna, "Do immigrants improve the health of natives?," Journal of Health Economics, 2015, 43, 140-153.

_ and Tianyi Wang, "Is an Army of Robots Marching on Chinese Jobs?," IZA Discussion Paper, 2019. 
_ , Fabrizio Mazzonna, Catia Nicodemo, and Carlos Vargas-Silva, "Immigration and the reallocation of work health risks," Journal of Population Economics, 2019, 32 (3), 1009-1042.

Goebel, Jan, Markus M. Grabka, Stefan Liebig, Martin Kroh, David Richter, Carsten Schröder, and Jürgen Schupp, “The German Socio-Economic Panel (SOEP)," Jahrbücher für Nationalökonomie und Statistik, 2019, 239 (2), 345 - 360.

Goldsmith-Pinkham, Paul, Isaac Sorkin, and Henry Swift, "Bartik instruments: What, when, why, and how," American Economic Review, 2020, 110 (8), 2586-2624.

Graetz, Georg and Guy Michaels, "Robots at work," Review of Economics and Statistics, 2018, 100 (5), 753-768.

Gunadi, Christian and Hanbyul Ryu, "Does the Rise of Robotic Technology Make People Healthier?," Technical Report, GLO Discussion Paper 2020.

Hummels, David, Jakob Munch, and Chong Xiang, "No pain, no gain: the effects of exports on effort, injury, and illness," Technical Report, National Bureau of Economic Research 2016.

Ishida, Hiroshi, Hidenao Tanaka, Haruki Taniguchi, and Toyosaka Moriizumi, "Mobile robot navigation using vision and olfaction to search for a gas/odor source," Autonomous Robots, 2006, 20 (3), 231-238.

Karwowski, Waldemar, Mansour Rahimi, and Tina Mihaly, "Effects of computerized automation and robotics on safety performance of a manufacturing plant," Journal of Occupational Accidents, 1988, 10 (3), 217-233.

Kirschgens, Laura Alzola, Irati Zamalloa Ugarte, Endika Gil Uriarte, Aday Muniz Rosas, and Víctor Mayoral Vilches, "Robot hazards: from safety to security," arXiv preprint arXiv:1806.06681, 2018.

Körner, Ulrike, Kathrin Müller-Thur, Thorsten Lunau, Nico Dragano, Peter Angerer, and Axel Buchner, "Perceived stress in human-machine interaction in modern manufacturing environments-Results of a qualitative interview study," Stress and Health, 2019, 35 (2), 187-199. 
Krause, Annabelle and Simone Schüller, "Evidence and persistence of education inequality in an early-tracking system. The German case," Scuola democratica, 2014, (2), 0-0.

Kroll, Lars Eric, "Construction and Validation of a General Index for Job Demands in Occupations Based on ISCO-88 and KIdB-92," METHODS DATA ANALYSES, 2011, 5 (1), 63-90.

Leombruni, Roberto, Tiziano Razzolini, and Francesco Serti, "The pecuniary and nonpecuniary costs of job displacement-The risky job of being back to work," European Economic Review, 2013, 61, 205-216.

Linsenmayer, Tadd, “ILO examines impact of technology on worker safety and health," 1985.

Matthias, Bjoern, Soenke Kock, Henrik Jerregard, Mats Kallman, Ivan Lundberg, and Roger Mellander, "Safety of collaborative industrial robots: Certification possibilities for a collaborative assembly robot concept," in "2011 IEEE International Symposium on Assembly and Manufacturing (ISAM)" Ieee 2011, pp. 1-6.

McManus, T Clay and Georg Schaur, "The effects of import competition on worker health," Journal of International Economics, 2016, 102, 160-172.

Neff, Roni A, Frank C Curriero, and Thomas A Burke, "Just in the wrong place... ?: Geographic tools for occupational injury/illness surveillance," American journal of industrial medicine, 2008, 51 (9), 680-690.

Peri, Giovanni and Chad Sparber, "Task specialization, immigration, and wages," American Economic Journal: Applied Economics, 2009, 1 (3), 135-69.

Robelski, Swantje and Sascha Wischniewski, "Human-machine interaction and health at work: a scoping review," International journal of human factors and ergonomics, 2018, 5 (2), 93-110.

Schneider, E and X Irastorza, "Work-related musculoskeletal disorders in the EU-Facts and Figures. European Agency for Safety and Health at Work," 2010.

SOEP, "SOEP-Core v34 - PGEN: Person-Related Status and Generated Variables," SOEP Survey Papers 758: SOEP Survey Papers : Series D - Variable Description and Coding, 2019. 
Szalma, James L and Grant S Taylor, "Individual differences in response to automation: The five factor model of personality.," Journal of Experimental Psychology: Applied, 2011, 17 (2), 71.

Venkataramani, Atheendar S, Elizabeth F Bair, Rourke L O’Brien, and Alexander C Tsai, “Association between automotive assembly plant closures and opioid overdose mortality in the United States: a difference-in-differences analysis," JAMA internal medicine, 2020, 180 (2), 254262.

Wagner, Gert G, Joachim R Frick, and Jürgen Schupp, “The German Socio-Economic Panel study (SOEP) - Scope, Evolution, and Enhancements," Schmollers Jahrbuch, 2007, 127, 139-169.

Zimmermann, Klaus F, Costanza Biavaschi, Werner Eichhorst, Corrado Giulietti, Michael J Kendzia, Alexander Muravyev, Janneke Pieters, Núria Rodríguez-Planas, Ricarda Schmidl et al., Youth unemployment and vocational training, Citeseer, 2013. 


\section{Appendix A: Supplemental Tables}

Table A.1: Descriptive Statistics in the US, 2005-2011

\begin{tabular}{lcc}
\hline \hline \multicolumn{1}{c}{ Mean } & Std dev \\
\hline \multicolumn{3}{c}{ Panel A: ODI dataset - Observations: 445,562} \\
\hline TCR & 7.13 & 8.23 \\
DART & 4.19 & 5.43 \\
DAFWII & 2.15 & 3.40 \\
& & \\
\hline
\end{tabular}

Panel B: CDC Data - Observations: 18,018

Deaths due to drug or alcohol abuse $388.56 \quad 124.97$

Suicide rate

$13.47 \quad 5.20$

Number of mentally unhealthy days $\quad 3.75 \quad 1.79$

Notes - Data are drawn from the ODI (OSHA) dataset in Panel A and from the CDC in Panel B (survey years: 2005-2011). The sample size of the suicide rate and number of mentally unhealthy days reduces to 2,819 and 14,945 observations, respectively. 
Table A.2: Effects of Robots Exposure on Workplace Injuries - Controlling for Trends in Low vs High Automotive Intensive Areas - 2SLS Estimates

\begin{tabular}{lccc}
\hline \hline & $(1)$ & $(2)$ & $(3)$ \\
& TCR & DART & DAFWII \\
\hline & & & \\
Robot exposure & $-1.072^{* * *}$ & $-0.909^{* * *}$ & 0.011 \\
& $(0.367)$ & $(0.254)$ & $(0.186)$ \\
& & & \\
Mean of dep. var. & 7.132 & 4.187 & 2.150 \\
Std. dev. of dep. var. & 8.235 & 5.429 & 3.398 \\
First stage F statistic & 298.2 & 298.2 & 298.2 \\
Observations & 445,562 & 445,562 & 445,562 \\
\hline \hline
\end{tabular}

Notes - Data are drawn from the ODI (OSHA) dataset (survey years: 2005-2011). The unit of observation is at the establishment-year level. All models control for commuting zone and year fixed effects and include non-linear specific time-trends across automotive intensive areas (below and above the median share of employment in the automative sector). Standard errors are reported in parentheses and are clustered at the commuting zone level.

*Significant at 10 per cent; ** Significant at 5 per cent; ***Significant at 1 per cent.

Table A.3: First stage: Effects of Robot Exposure IV on Robot Exposure

\begin{tabular}{lc}
\hline \hline & $(1)$ \\
Dep. var.: & Robot exposure \\
\hline Robot exposure - IV & $0.423^{* * *}$ \\
& $(0.016)$ \\
& \\
Observations & 445,562 \\
Mean of dep. var. & 0 \\
Std. dev. of dep. var. & 1 \\
\hline \hline
\end{tabular}

Notes - Data are drawn from the ODI (OSHA) dataset (survey years: 2005-2011). The unit of observation is at the establishment-year level. All models control for commuting zone and year fixed effects. Standard errors are reported in parentheses and are clustered at the commuting zone level.

*Significant at 10 per cent; ** Significant at 5 per cent; ***Significant at 1 per cent. 
Table A.4: Effects of Robot Exposure on Workplace Injuries - Adding State-Specific Time Trends

\begin{tabular}{|c|c|c|c|}
\hline & $\begin{array}{c}(1) \\
\text { OLS }\end{array}$ & $\begin{array}{c}(2) \\
\text { Reduced form }\end{array}$ & $\begin{array}{c}(3) \\
\text { 2SLS }\end{array}$ \\
\hline \multicolumn{4}{|c|}{ Panel A: Dep. var.: TCR } \\
\hline Robot exposure & $\begin{array}{c}-1.575^{* * *} \\
(0.377)\end{array}$ & & $\begin{array}{c}-1.185^{* * *} \\
(0.321)\end{array}$ \\
\hline Robot exposure - IV & & $\begin{array}{c}-0.501^{* * *} \\
(0.139)\end{array}$ & \\
\hline $\begin{array}{l}\text { Mean of dep. var. } \\
\text { Std. dev. of dep. var. } \\
\text { First stage F statistic }\end{array}$ & $\begin{array}{l}7.132 \\
8.235\end{array}$ & $\begin{array}{l}7.132 \\
8.235\end{array}$ & $\begin{array}{l}7.132 \\
8.235 \\
690.5\end{array}$ \\
\hline \multicolumn{4}{|c|}{ Panel B: Dep. var.: DART } \\
\hline Robot exposure & $\begin{array}{c}-1.013^{* * *} \\
(0.226)\end{array}$ & & $\begin{array}{c}-0.847^{* * *} \\
(0.207)\end{array}$ \\
\hline Robot exposure - IV & & $\begin{array}{c}-0.358^{* * *} \\
(0.088)\end{array}$ & \\
\hline $\begin{array}{l}\text { Mean of dep. var. } \\
\text { Std. dev. of dep. var. } \\
\text { First stage F statistic }\end{array}$ & $\begin{array}{l}4.187 \\
5.429\end{array}$ & $\begin{array}{l}4.187 \\
5.429\end{array}$ & $\begin{array}{l}4.187 \\
5.429 \\
690.5\end{array}$ \\
\hline \multicolumn{4}{|c|}{ Panel C: Dep. var.: DAFWII } \\
\hline Robot exposure & $\begin{array}{l}-0.016 \\
(0.151)\end{array}$ & & $\begin{array}{c}0.135 \\
(0.132)\end{array}$ \\
\hline Robot exposure - IV & & $\begin{array}{c}0.057 \\
(0.057)\end{array}$ & \\
\hline $\begin{array}{l}\text { Mean of dep. var. } \\
\text { Std. dev. of dep. var. } \\
\text { First stage F statistic }\end{array}$ & $\begin{array}{l}2.150 \\
3.398\end{array}$ & $\begin{array}{l}2.150 \\
3.398\end{array}$ & $\begin{array}{l}2.150 \\
3.398 \\
690.5\end{array}$ \\
\hline Observations & 445,562 & 445,562 & 445,562 \\
\hline
\end{tabular}

Notes - Data are drawn from the ODI (OSHA) dataset (survey years: 2005-2011). The unit of observation is at the establishment-year level. All models control for commuting zone and year fixed effects, and state-specific time trends.Standard errors are reported in parentheses and are clustered at the commuting zone level.

*Significant at 10 per cent; ${ }^{* *}$ Significant at 5 per cent; ${ }^{* * * S i g n i f i c a n t ~ a t ~} 1$ per cent. 
Table A.5: Effects of Robot Exposure (Lagged by One Year) on Workplace Injuries

\begin{tabular}{|c|c|c|c|}
\hline & $\begin{array}{l}(1) \\
\text { OLS }\end{array}$ & $\begin{array}{c}\text { (2) } \\
\text { Reduced form }\end{array}$ & $\begin{array}{c}(3) \\
\text { 2SLS }\end{array}$ \\
\hline \multicolumn{4}{|c|}{ Panel A: Dep. var.: TCR } \\
\hline Robot exposure $(t-1)$ & $\begin{array}{c}-1.580^{* * *} \\
(0.362)\end{array}$ & & $\begin{array}{c}-1.063^{* * *} \\
(0.330)\end{array}$ \\
\hline Robot exposure - IV $(t-1)$ & & $\begin{array}{c}-0.438^{* * *} \\
(0.136)\end{array}$ & \\
\hline $\begin{array}{l}\text { Mean of dep. var. } \\
\text { Std. dev. of dep. var. } \\
\text { First stage F statistic }\end{array}$ & $\begin{array}{l}6.886 \\
8.248\end{array}$ & $\begin{array}{l}6.886 \\
8.248\end{array}$ & $\begin{array}{l}6.886 \\
8.248 \\
470.9\end{array}$ \\
\hline \multicolumn{4}{|c|}{ Panel B: Dep. var.: DART } \\
\hline Robot exposure $(t-1)$ & $\begin{array}{c}-0.971^{* * *} \\
(0.178)\end{array}$ & & $\begin{array}{c}-0.760^{* * *} \\
(0.201)\end{array}$ \\
\hline Robot exposure - IV $(t-1)$ & & $\begin{array}{c}-0.314^{* * *} \\
(0.083)\end{array}$ & \\
\hline $\begin{array}{l}\text { Mean of dep. var. } \\
\text { Std. dev. of dep. var. } \\
\text { First stage F statistic }\end{array}$ & $\begin{array}{l}4.033 \\
5.406\end{array}$ & $\begin{array}{l}4.033 \\
5.406\end{array}$ & $\begin{array}{l}4.033 \\
5.406 \\
470.9\end{array}$ \\
\hline \multicolumn{4}{|c|}{ Panel C: Dep. var.: DAFWII } \\
\hline Robot exposure $(t-1)$ & $\begin{array}{c}0.012 \\
(0.113)\end{array}$ & & $\begin{array}{c}0.081 \\
(0.139)\end{array}$ \\
\hline Robot exposure - IV $(t-1)$ & & $\begin{array}{c}0.033 \\
(0.058)\end{array}$ & \\
\hline $\begin{array}{l}\text { Mean of dep. var. } \\
\text { Std. dev. of dep. var. } \\
\text { First stage F statistic }\end{array}$ & $\begin{array}{l}2.085 \\
3.380\end{array}$ & $\begin{array}{l}2.085 \\
3.380\end{array}$ & $\begin{array}{l}2.085 \\
3.380 \\
470.9\end{array}$ \\
\hline Observations & 383,291 & 383,291 & 383,291 \\
\hline
\end{tabular}

Notes - Data are drawn from the ODI (OSHA) dataset (survey years: 2005-2011). The unit of observation is at the establishment-year level. All models control for commuting zone and year fixed effects. Standard errors are reported in parentheses and are clustered at the commuting zone level.

*Significant at 10 per cent; ** Significant at 5 per cent; ${ }^{* * *}$ Significant at 1 per cent. 
Table A.6: Effects of Robot Exposure on Workplace Injuries - Adding Controls

\begin{tabular}{lccc}
\hline \hline & $(1)$ & $(2)$ & $(3)$ \\
& OLS & Reduced form & 2SLS \\
\hline \multicolumn{4}{c}{ Panel A: Dep. var.: TCR } \\
\hline Robot exposure & $-1.553^{* * *}$ & & \\
& $(0.366)$ & & $-1.163^{* * *}$ \\
Robot exposure - IV & & $-0.491^{* * *}$ & $(0.312)$ \\
& & $(0.135)$ & \\
Mean of dep. var. & 7.132 & 7.132 & 7.132 \\
Std. dev. of dep. var. & 8.235 & 8.235 & 8.235 \\
First stage F statistic & & & 692.7 \\
& & & \\
\hline
\end{tabular}

Panel B: Dep. var.: DART

\begin{tabular}{|c|c|c|c|}
\hline Robot exposure & $\begin{array}{c}-1.033^{* * *} \\
(0.227)\end{array}$ & & $\begin{array}{c}-0.865^{* * *} \\
(0.208)\end{array}$ \\
\hline Robot exposure - IV & & $\begin{array}{c}-0.365^{* * *} \\
(0.088)\end{array}$ & \\
\hline $\begin{array}{l}\text { Mean of dep. var. } \\
\text { Std. dev. of dep. var. } \\
\text { First stage F statistic }\end{array}$ & $\begin{array}{l}4.187 \\
5.429\end{array}$ & $\begin{array}{l}4.187 \\
5.429\end{array}$ & $\begin{array}{l}4.187 \\
5.429 \\
692.7\end{array}$ \\
\hline \multicolumn{4}{|c|}{ Panel C: Dep. var.: DAFWII } \\
\hline Robot exposure & $\begin{array}{l}-0.060 \\
(0.162)\end{array}$ & & $\begin{array}{c}0.088 \\
(0.142)\end{array}$ \\
\hline Robot exposure - IV & & $\begin{array}{c}0.037 \\
(0.061)\end{array}$ & \\
\hline $\begin{array}{l}\text { Mean of dep. var. } \\
\text { Std. dev. of dep. var. } \\
\text { 2-3 First stage F statistic }\end{array}$ & $\begin{array}{l}2.150 \\
3.398\end{array}$ & $\begin{array}{l}2.150 \\
3.398\end{array}$ & $\begin{array}{l}2.150 \\
3.398 \\
692.7\end{array}$ \\
\hline Observations & 445,562 & 445,562 & 445,562 \\
\hline
\end{tabular}

Notes - Data are drawn from the ODI (OSHA) dataset (survey years: 2005-2011). The unit of observation is at the establishment-year level. All models control for commuting zone and year fixed effects, as well as commuting-zone level controls, such as the share of women, the average age and the proportion of individuals with a college degree. Standard errors are reported in parentheses and are clustered at the commuting zone level.

*Significant at 10 per cent; ${ }^{* *}$ Significant at 5 per cent; ***Significant at 1 per cent. 
Table A.7: Effects of Robot Exposure on Workplace Injuries - Reduced Form, 1996-2011

\begin{tabular}{lcc}
\hline \hline & $(1)$ & $(2)$ \\
Dep. var.: & TCR & DART \\
\hline Robot exposure - IV & $-0.782^{* * *}$ & $-0.529^{* * *}$ \\
& $(0.076)$ & $(0.052)$ \\
& & \\
& & \\
Observations & 960,675 & 960,677 \\
Mean of dep. var. & 9.846 & 5.502 \\
Std. dev. of dep. var. & 17.83 & 14.55 \\
\hline \hline
\end{tabular}

Notes - Data are drawn from the ODI (OSHA) dataset (survey years: 1996-2011). The unit of observation is at the establishment-year level. All models control for commuting zone and year fixed effects. Standard errors are reported in parentheses and are clustered at the commuting zone level.

*Significant at 10 per cent; ** Significant at 5 per cent; ***Significant at 1 per cent.

Table A.8: Effects of Robot Exposure on Workplace Injuries - Reduced Form, 1996-2007

\begin{tabular}{lcc}
\hline \hline & $(1)$ & $(2)$ \\
Dep. var.: & TCR & DART \\
\hline & & \\
Robot exposure - IV & $-0.826^{* * *}$ & $-0.555^{* * *}$ \\
& $(0.103)$ & $(0.089)$ \\
& & \\
& & \\
Observations & 703,448 & 703,450 \\
Mean of dep. var. & 11.16 & 6.185 \\
Std. dev. of dep. var. & 20.03 & 16.62 \\
\hline \hline
\end{tabular}

Notes - Data are drawn from the ODI (OSHA) dataset (survey years: 1996-2007). The unit of observation is at the establishment-year level. All models control for commuting zone and year fixed effects. Standard errors are reported in parentheses and are clustered at the commuting zone level.

*Significant at 10 per cent; ** Significant at 5 per cent; ***Significant at 1 per cent. 
Table A.9: Effects of Robot Exposure on Workplace Injuries - 2SLS Estimates

\begin{tabular}{|c|c|c|c|}
\hline Dep. var.: & $\begin{array}{c}(1) \\
\text { TCR }\end{array}$ & $\begin{array}{c}(2) \\
\text { DART }\end{array}$ & $\begin{array}{c}(3) \\
\text { DAFWII }\end{array}$ \\
\hline \multicolumn{4}{|c|}{ Panel A: Including establishment FE } \\
\hline Robot exposure & $\begin{array}{c}-1.078^{* * *} \\
(0.413)\end{array}$ & $\begin{array}{c}-0.768^{* * *} \\
(0.293)\end{array}$ & $\begin{array}{c}0.113 \\
(0.216)\end{array}$ \\
\hline $\begin{array}{l}\text { Observations } \\
\text { Mean of dep. var. } \\
\text { Std. dev. of dep. var. } \\
\text { First stage F statistic }\end{array}$ & $\begin{array}{c}387,829 \\
7.409 \\
7.953 \\
647.7\end{array}$ & $\begin{array}{c}387,829 \\
4.398 \\
5.490 \\
647.7\end{array}$ & $\begin{array}{c}387,829 \\
2.231 \\
3.425 \\
647.7\end{array}$ \\
\hline \multicolumn{4}{|c|}{ Panel B: Sector-level robot exposure } \\
\hline Robot exposure (sector-level) & $\begin{array}{c}-1.649^{* *} \\
(0.713)\end{array}$ & $\begin{array}{c}-0.924^{* *} \\
(0.445)\end{array}$ & $\begin{array}{c}-0.130 \\
(0.249)\end{array}$ \\
\hline Observations & 360,730 & 360,730 & 360,730 \\
\hline Mean of dep. var. & 7.625 & 4.554 & 2.284 \\
\hline Std. dev. of dep. var. & 8.449 & 5.587 & 3.437 \\
\hline First stage F statistic & 15.71 & 15.71 & 15.71 \\
\hline
\end{tabular}

Notes - Data are drawn from the ODI (OSHA) dataset (survey years: 2005-2011). The unit of observation is at the establishment-year level. Panels A and B control for establishment fixed effects and year dummies. Standard errors are reported in parentheses and are clustered at the commuting zone level in Panel A, and IFR sector and year in Panel B.

*Significant at 10 per cent; ** Significant at 5 per cent; ***Significant at 1 per cent. 
Table A.10: Descriptive Statistics in Germany, 1994-2016 - Observations: 64,358

\begin{tabular}{lcc}
\hline \hline & Mean & Std. dev. \\
\hline Disability & 0.064 & 0.244 \\
Work accidents & 0.057 & 0.231 \\
High physical intensity & 0.210 & 0.408 \\
High psychological intensity & 0.187 & 0.390 \\
Work satisfaction & 6.897 & 1.936 \\
Life satisfaction & 6.931 & 1.611 \\
Age & 43.937 & 10.134 \\
Female & 0.445 & 0.497 \\
Married & 0.718 & 0.450 \\
Lower secondary education (basic track) & 0.333 & 0.471 \\
Medium secondary education (intermediate track) & 0.391 & 0.488 \\
Higher secondary education (academic track) & 0.200 & 0.400 \\
\hline \hline
\end{tabular}

Notes - Data are drawn from the SOEP for individuals aged 18-64 years (survey years: 1994-2016). All the samples contain individuals for whom information on all observables and the respective outcome variable are not missing. The sample size of work accidents, high physical (psychological) burden, work satisfaction and life satisfaction reduces respectively to 26,925, 63,886, 63,231 and 64,228, respectively.

Table A.11: Effects of Robot Exposure in Germany - Exposure based on Vocational Training

\begin{tabular}{|c|c|c|c|c|c|c|}
\hline Dep. var.: & $\begin{array}{c}(1) \\
\text { Disability }\end{array}$ & $\begin{array}{c}(2) \\
\text { Total burden }\end{array}$ & $\begin{array}{c}\text { (3) } \\
\text { High physical burden }\end{array}$ & $\begin{array}{c}(4) \\
\text { High psychological burden }\end{array}$ & $\begin{array}{c}(5) \\
\text { Work satisfaction }\end{array}$ & $\begin{array}{c}(6) \\
\text { Life satisfaction }\end{array}$ \\
\hline Robot exposure & $\begin{array}{l}-0.016^{* *} \\
(0.006)\end{array}$ & $\begin{array}{l}-0.005 \\
(0.011)\end{array}$ & $\begin{array}{l}-0.026^{* *} \\
(0.012)\end{array}$ & $\begin{array}{l}-0.013 \\
(0.012)\end{array}$ & $\begin{array}{c}0.354^{* * *} \\
(0.118)\end{array}$ & $\begin{array}{l}-0.010 \\
(0.085)\end{array}$ \\
\hline Observations & 33,266 & 33,001 & 33,001 & 33,001 & 31,701 & 32,316 \\
\hline Mean of dep. var. & 0.048 & 0.204 & 0.173 & 0.199 & 7.212 & 7.446 \\
\hline Std. dev. of dep. var. & 0.213 & 0.403 & 0.379 & 0.400 & 2.029 & 1.598 \\
\hline
\end{tabular}

Notes - Data are drawn from the SOEP. The unit of observation is at the individual-year level. All models control for age dummies, indicators for education, martial status, state dummies, as well as year and individual fixed effects. Standard errors are reported in parentheses and are clustered at IFR sector and year.

*Significant at 10 per cent; ${ }^{* *}$ Significant at 5 per cent; ${ }^{* * * S i g n i f i c a n t ~ a t ~} 1$ per cent. 